\title{
IMI - Oral Biopharmaceutics Tools project - Evaluation of Bottom-up PBPK Prediction Success Part 2: An Introduction to the Simulation Exercise and Overview of Results
}

DOI:

10.1016/j.ejps.2016.10.036

Document Version

Accepted author manuscript

Link to publication record in Manchester Research Explorer

\section{Citation for published version (APA):}

Margolskee, A., Darwich, A., Aarons, L., Galetin, A., Rostami-Hochaghan, A., Carlert, S., Hammarberg, M., Hilgendorf, C., Johansson, P., Karlsson, E., Murphy, D., Tannergren, C., Thorn, H., Yasin, M., Mazuir, F., Nicolas, O., Ramusovic, S., Xu, C., Pathak, S., ... Abrahamsson, B. (2016). IMI - Oral Biopharmaceutics Tools project Evaluation of Bottom-up PBPK Prediction Success Part 2: An Introduction to the Simulation Exercise and Overview of Results. European Journal of Pharmaceutical Sciences. https://doi.org/10.1016/j.ejps.2016.10.036

Published in:

European Journal of Pharmaceutical Sciences

\section{Citing this paper}

Please note that where the full-text provided on Manchester Research Explorer is the Author Accepted Manuscript or Proof version this may differ from the final Published version. If citing, it is advised that you check and use the publisher's definitive version.

\section{General rights}

Copyright and moral rights for the publications made accessible in the Research Explorer are retained by the authors and/or other copyright owners and it is a condition of accessing publications that users recognise and abide by the legal requirements associated with these rights.

\section{Takedown policy}

If you believe that this document breaches copyright please refer to the University of Manchester's Takedown Procedures [http://man.ac.uk/04Y6Bo] or contact uml.scholarlycommunications@manchester.ac.uk providing relevant details, so we can investigate your claim. 


\section{Accepted Manuscript}

IMI - Oral Biopharmaceutics Tools project - Evaluation of Bottom-up PBPK Prediction Success Part 2: An Introduction to the Simulation Exercise and Overview of Results

Alison Margolskee, Adam S. Darwich, Xavier Pepin, Leon Aarons, Aleksandra Galetin, Amin Rostami-Hodjegan, Sara Carlert, Maria Hammarberg, Constanze Hilgendorf, Pernilla Johansson, Eva Karlsson, Dónal Murphy, Christer Tannergren, Helena Thörn, Mohammed Yasin, Florent Mazuir, Olivier Nicolas, Sergej Ramusovic, Christine Xu, Shriram M. Pathak, Timo Korjamo, Johanna Laru, Jussi Malkki, Sari Pappinen, Johanna Tuunainen, Jennifer Dressman, Simone Hansmann, Edmund Kostewicz, Handan He, Tycho Heimbach, Fan Wu, Carolin Hoft, Loic Laplanche, Yan Pang, Michael B. Bolger, Eva Huehn, Viera Lukacova, James M. Mullin, Ke X. Szeto, Chester Costales, Jian Lin, Mark McAllister, Sweta Modi, Charles Rotter, Manthena Varma, Mei Wong, Amitava Mitra, Jan Bevernage, Jeike Biewenga, Achiel Van Peer, Richard Lloyd, Carole Shardlow, Peter Langguth, Irina Mishenzon, Mai Anh Nguyen, Jonathan Brown, Hans Lennernäs, Bertil Abrahamsson

PII: $\quad$ S0928-0987(16)30476-6

DOI: $\quad$ doi: $10.1016 / j . e j p s .2016 .10 .036$

Reference: $\quad$ PHASCI 3782

To appear in:

Received date: 10 May 2016

Revised date: 12 October 2016

Accepted date: $\quad 30$ October 2016

Please cite this article as: Margolskee, Alison, Darwich, Adam S., Pepin, Xavier, Aarons, Leon, Galetin, Aleksandra, Rostami-Hodjegan, Amin, Carlert, Sara, Hammarberg, Maria, Hilgendorf, Constanze, Johansson, Pernilla, Karlsson, Eva, Murphy, Dónal, Tannergren, Christer, Thörn, Helena, Yasin, Mohammed, Mazuir, Florent, Nicolas, Olivier, Ramusovic, Sergej, Xu, Christine, Pathak, Shriram M., Korjamo, Timo, Laru, Johanna, Malkki, Jussi, Pappinen, Sari, Tuunainen, Johanna, Dressman, Jennifer, Hansmann, Simone, Kostewicz, Edmund, He, Handan, Heimbach, Tycho, Wu, Fan, Hoft, Carolin, Laplanche, Loic, Pang, Yan, Bolger, Michael B., Huehn, Eva, Lukacova, Viera, Mullin, James M., Szeto, Ke X., Costales, Chester, Lin, Jian, McAllister, Mark, Modi, Sweta, Rotter, Charles, Varma, Manthena, Wong, Mei, Mitra, Amitava, Bevernage, Jan, Biewenga, Jeike, Van Peer, Achiel, Lloyd, Richard, Shardlow, Carole, Langguth, Peter, Mishenzon, Irina, Nguyen, Mai Anh, Brown, Jonathan, Lennernäs, Hans, Abrahamsson, Bertil, IMI - Oral Biopharmaceutics Tools project - Evaluation of Bottom-up PBPK Prediction Success Part 2: An Introduction to the Simulation Exercise and Overview of Results, (2016), doi:10.1016/j.ejps.2016.10.036 


\section{IMI - Oral Biopharmaceutics Tools project - Evaluation of Bottom-up PBPK Prediction Success Part 2: An Introduction to the Simulation Exercise and Overview of Results}

Alison Margolskee ${ }^{1}$,Adam S. Darwich ${ }^{1}$, Xavier Pepin ${ }^{2,3}$, Leon Aarons ${ }^{1}$, Aleksandra Galetin ${ }^{1}$, Amin Rostami-Hodjegan ${ }^{1,4}$, Sara Carlert ${ }^{5}$, Maria Hammarberg ${ }^{5}$, Constanze Hilgendorf ${ }^{5}$, Pernilla Johansson ${ }^{5}$, Eva Karlsson ${ }^{5}$, Dónal Murphy, ${ }^{2}$, Christer Tannergren ${ }^{5}$, Helena Thörn ${ }^{5}$, Mohammed Yasin ${ }^{2}$, Florent Mazuir ${ }^{3}$, Olivier Nicolas, ${ }^{3}$ Sergej Ramusovic ${ }^{6}$, Christine Xu, Shriram M. Pathak ${ }^{4}$, Timo Korjamo ${ }^{8}$, Johanna Laru ${ }^{2,8}$, Jussi Malkki ${ }^{8}$, Sari Pappinen ${ }^{8}$, Johanna Tuunainen ${ }^{8}$, Jennifer Dressman ${ }^{9}$, Simone Hansmann ${ }^{9}$, Edmund Kostewicz ${ }^{9}$, Handan $\mathrm{He}^{10}$, Tycho Heimbach ${ }^{10}, \mathrm{Fan} \mathrm{Wu}^{10}$, Carolin Hoft ${ }^{11}$, Loic Laplanche ${ }^{11}$, Yan Pang ${ }^{11}$, Michael B. Bolger ${ }^{12}$, Eva Huehn ${ }^{12}$, Viera Lukacova ${ }^{12}$,James M. Mullin ${ }^{12}$, Ke X. Szeto ${ }^{12}$, Chester Costales $^{13}$, Jian Lin ${ }^{13}$, Mark McAllister ${ }^{14}$, Sweta Modi ${ }^{13}$, Charles Rotter ${ }^{13}$, Manthena Varma $^{14}$, Mei Wong ${ }^{14}$, Amitava Mitra ${ }^{15}$, Jan Bevernage ${ }^{16}$, Jeike Biewenga ${ }^{16}$, Achiel Van Peer $^{16}$, Richard Lloyd ${ }^{17}$, Carole Shardlow ${ }^{17}$, Peter Langguth ${ }^{18}$, Irina Mishenzon ${ }^{18}$, Mai Anh Nguyen $^{18}$, Jonathan Brown ${ }^{19}$, Hans Lennernäs ${ }^{20}$, Bertil Abrahamsson ${ }^{5}$

${ }^{1}$ University of Manchester, United Kingdom

${ }^{2}$ AstraZeneca, United Kingdom

${ }^{3}$ Sanofi, France

${ }^{4}$ Simcyp Ltd, United Kingdom

${ }^{5}$ AstraZeneca, Sweden

${ }^{2}$ AstraZeneca, United Kingdom

${ }^{3}$ Sanofi, France

${ }^{6}$ Sanofi, Germany

${ }^{7}$ Sanofi, United States

${ }^{8}$ Orion Pharma, Finland

${ }^{9}$ Goethe University Frankfurt am Main, Germany

${ }^{10}$ Novartis, United States

${ }^{11}$ AbbVie, Germany 
${ }^{12}$ Simulations Plus, Inc., United States

${ }^{13}$ Pfizer, United States

${ }^{14}$ Pfizer, United Kingdom

${ }^{15}$ Merck Sharp \& Dohme (MSD), United Kingdom

${ }^{16}$ Janssen, Belgium

${ }^{17}$ GlaxoSmithKline, United Kingdom

${ }^{18}$ Johannes Gutenberg University of Mainz, Germany

${ }^{19}$ Bristol-Myers Squibb, United Kingdom

${ }^{20}$ Uppsala University, Sweden

\section{Graphical Abstract}

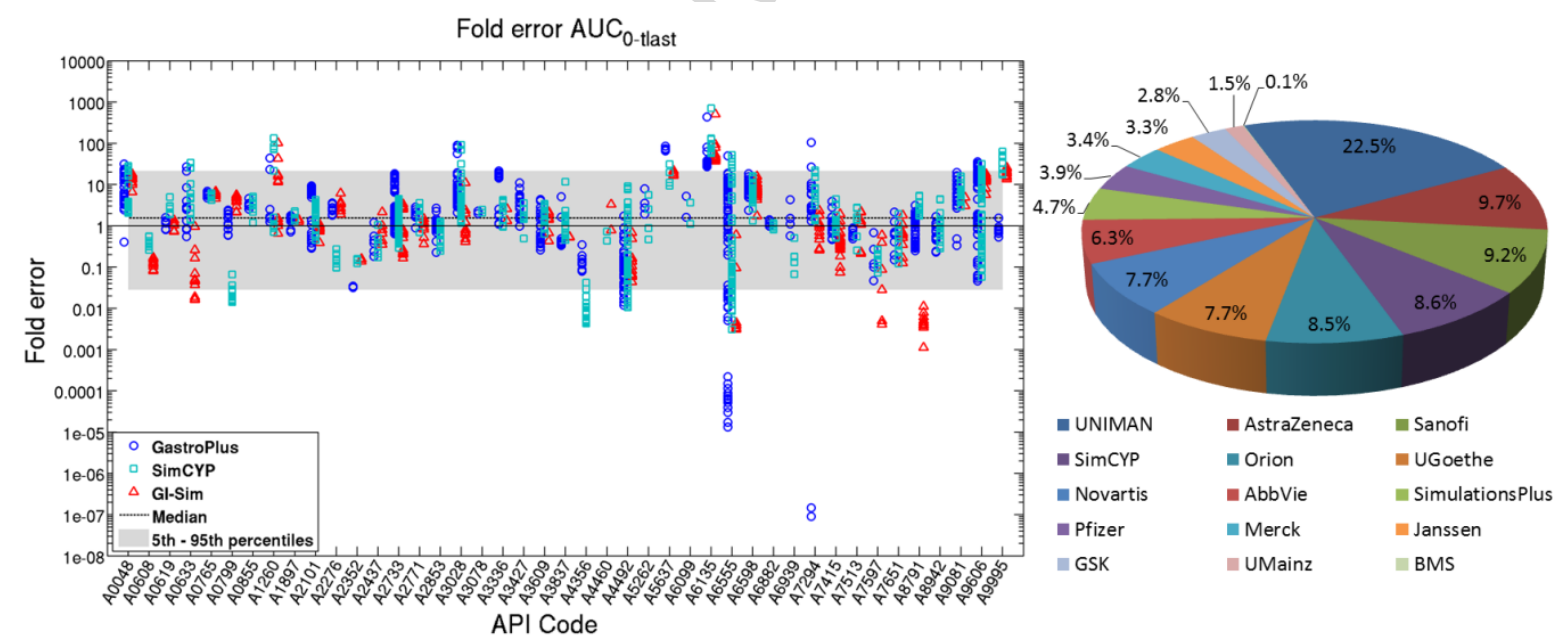

\section{Abstract}

Orally administered drugs are subject to a number of barriers impacting bioavailability $\left(\mathrm{F}_{\text {oral }}\right)$, causing challenges during drug and formulation development. Physiologically-based pharmacokinetic (PBPK) modelling can help during drug and formulation development by providing quantitative predictions through a systems approach. The performance of three 
available PBPK software packages (GI-Sim, Simcyp ${ }^{\circledR}$, and GastroPlus ${ }^{\mathrm{TM}}$ ) were evaluated by comparing simulated and observed pharmacokinetic (PK) parameters.

Since the availability of input parameters was heterogeneous and highly variable, caution is required when interpreting the results of this exercise. Additionally, this prospective simulation exercise may not be representative of prospective modelling in industry, as API information was limited to sparse details.

43 active pharmaceutical ingredients (APIs) from the OrBiTo database were selected for the exercise. Over 4,000 simulation output files were generated, representing over 2,550 study arm-institution-software combinations and approximately 600 human clinical study arms simulated with overlap. $84 \%$ of the simulated study arms represented administration of immediate release formulations, $11 \%$ prolonged or delayed release, and 5\% intravenous (i.v.).

Higher percentages of i.v. predicted area under the curve (AUC) were within two-fold of observed (52.9\%) compared to per oral (p.o.) (37.2\%), however, $\mathrm{F}_{\text {oral }}$ and relative AUC $\left(\mathrm{F}_{\text {rel }}\right)$ between p.o. formulations and solutions were generally well predicted (64.7\% and $75.0 \%)$. Predictive performance declined progressing from i.v. to solution and immediate release tablet, indicating the compounding error with each layer of complexity. Overall performance was comparable to previous large-scale evaluations.

A general overprediction of AUC was observed with average fold error (AFE) of 1.56 over all simulations. AFE ranged from 0.0361 to 64.0 across the 43 APIs, with 25 showing overpredictions. Discrepancies between software packages were observed for a few APIs, the largest being 606, 171, and 81.7-fold differences in AFE between SimCYP and GI-Sim, however average performance was relatively consistent across the three software platforms. 


\section{Keywords:}

Physiologically-based pharmacokinetics (PBPK); modelling and simulation (M\&S); absorption; oral bioavailability $\left(\mathrm{F}_{\text {oral }}\right)$; biopharmaceutics; drug database

\section{Abbreviations:}

API = Active pharmaceutical ingredient,

$\mathrm{AUC}=$ Area under the curve,

$\mathrm{BCS}=$ Biopharmaceutics classification system,

$\mathrm{BE}=$ Bioequivalence

$\mathrm{BP}=$ Blood-to-plasma ratio,

$\mathrm{CL}=$ Clearance,

$\mathrm{CL} / \mathrm{F}=$ Apparent clearance

$\mathrm{C}_{\max }=$ Maximum concentration,

$\mathrm{D}_{\mathrm{o}}=$ Dose number,

$\mathrm{f}_{\mathrm{a}}=$ Fraction absorbed,

FIM = First In Man

$\mathrm{F}_{\text {oral }}=$ Absolute oral bioavailability,

$\mathrm{F}_{\text {rel }}=$ Relative bioavailability,

$\mathrm{f}_{\mathrm{up}}=$ fraction unbound in plasma, 
$\mathrm{IMI}=$ Innovative Medicines Initiative,

i.v. $=$ Intravenous,

$\mathrm{IR}=$ Immediate release,

$\log \mathrm{P}=\mathrm{Logarithm}$ of the octanol/water partition coefficient,

$\log \mathrm{D}_{\mathrm{pH}}=\operatorname{Logarithm}$ of the octanol/water partition coefficient at a given $\mathrm{pH}$,

MTD = Maximal Tolerated Dose

$\mathrm{MW}=$ Molecular weight,

PBPK = Physiologically-based pharmacokinetic,

PAC $=$ Post Approval Changes

PK $=$ Pharmacokinetic,

p.o. $=$ per oral,

$\mathrm{QbD}=$ Quality by Design

$\mathrm{SME}=$ Small or Medium Enterprise

$\mathrm{t}_{\max }=$ Time at maximum concentration,

$\mathrm{V}_{\mathrm{d}}=$ Volume of distribution,

$\mathrm{V}_{\mathrm{d}} / \mathrm{F}=$ Apparent volume of distribution, 


\section{Introduction}

The oral route is considered the most favourable for drug administration, however orally administered drugs are subject to a number of barriers that may result in variable oral bioavailability $\left(\mathrm{F}_{\text {oral }}\right)$ and systemic exposure. Such barriers include dissolution and potential precipitation in the gut lumen, chemical or enzymatic drug degradation, binding to constituents of the lumen, permeation through the gut wall, intestinal influx/efflux and intestinal and hepatic first-pass metabolism, to name the most crucial. These barriers have the potential to cause considerable challenges in drug and formulation development due to unexpected behaviour in oral drug exposure. Physiologically-based pharmacokinetic (PBPK) modelling and simulation (M\&S) may aid biopharmaceutical development, in a manner similar to its role in the prediction of drug-drug interactions (Messier, 1960; Kostewicz et al., 2013). PBPK M\&S can provide rationale and insight into the key underlying processes governing oral exposure and ultimately provide quantitative predictions of biopharmaceutic exposure through a systems approach i.e., with the incorporation of in vitro and in vivo data (Huang et al., 2013; Thondre et al., 2013). This information is utilised throughout the drug development value chain within the pharmaceutical industry to make informed decisions around key milestones and, under certain conditions, to waive some in vivo human evaluations in late stage development. 




Figure 1: The role of in silico modelling in the oral formulation and drug development value chain. $\mathrm{BE}=$ Bioequivalence $\mathrm{QbD}=$ quality by design; $\mathrm{PAC}=$ post approval changes

At the time of drug pre-candidate selection, the ability of different compounds to be used commercially as pharmaceutical drugs can be assessed in silico to aid in selecting the best candidate to develop (Bueters et al., 2013). This decision is based on measured in vivo preclinical or in vitro drug efficacy, and predicted human in vivo absorption, first pass intestinal and hepatic extraction, distribution and elimination. It is also used to guide formulation scientists in the first in man (FIM) formulation choice and development, and alert them to possible limitations such as particle size, potential in vivo precipitation or degradation, or permeability limitations, in order to decide on the best formulation strategy and potential impact of certain excipients (Figure 1) (Willmann et al., 2010; Mitra et al., 2011; Chen et al., 2012).

Once human data have been generated the PBPK M\&S models are refined with additional inputs, and can be used to define the best commercial formulation strategy. Throughout the 
development value chain, in silico models can be used to assist the quality by design and drug product control strategies (Bredael et al., 2014; Yu et al., 2014; Kesisoglou et al., 2015). In particular, they can help justify the specifications and method used for dissolution testing of the drug product together with the specifications for particle size or the acceptance level of another polymorph in the formulation. During the approval process, modelling can be used to support responses to regulatory authorities and, in post approval, to justify changes that are beyond the current Scale Up and Post Approval Changes (SUPAC) guidances (Johnson et al., 2014; Pepin et al., 2016).

In the field of generic formulations or life cycle management, most of the human data are known and the inputs needed for PBPK M\&S tools can be found in the literature or can be generated in vitro. The in silico tools can therefore be used at the ideation stage to define the best dose/release profile/formulation properties that could increase the medical value of the marketed drug (e.g. through reduction of side effects or increase in efficacy/robustness). The tools are also used to assist prototype selection and anticipate the outcome of bioequivalence studies (Figure 2). 


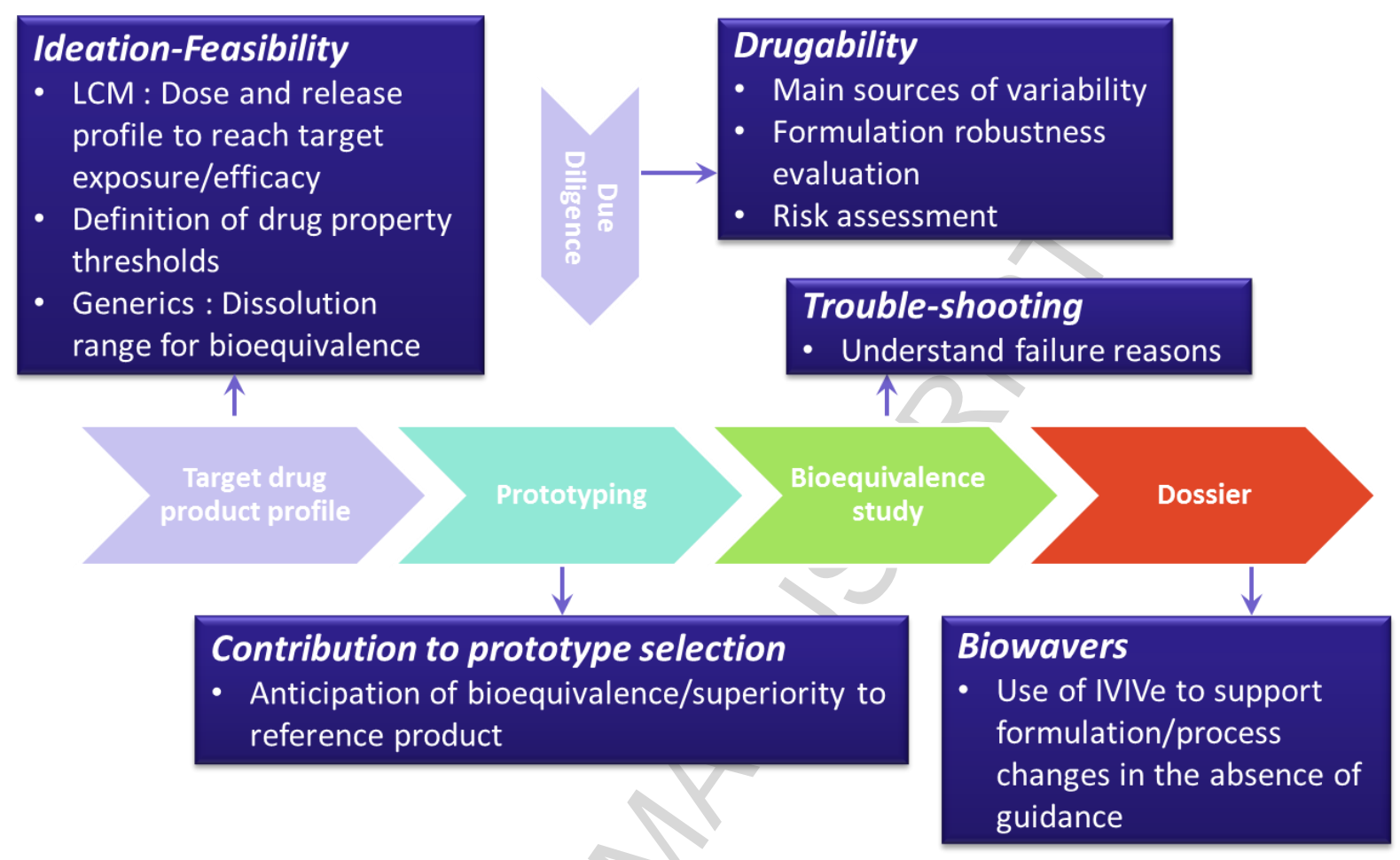

Figure 2: The role of in silico modelling in late stage formulation development and generics.

$(\mathrm{LCM}=$ life cycle management; IVIVe = in vitroin vivo extrapolation $)$

Today, such late stage use of PBPK M\&S for oral absorption modelling are not routine in the industry or for the regulators and need to be justified/validated with in vivo data on similar formulations of the drug tested in humans. Examples of biowaivers based on in silico modelling for oral formulations are limited in the literature. The IMI (Innovative Medicines Initiative) OrBiTo (Oral Biopharmaceutical Tools) project attempts to address that gap through a holistic approach of data-sharing, refinement of in vitro and in silico tools and the integration of novel understanding of the gastrointestinal (GI) tract physiology (Lennernas et al., 2013).

In our previous work (Margolskee et al. - Part 1 - Submitted) we demonstrated the setup and characteristics of the OrBiTo database of APIs (active pharmaceutical ingredients), which contained drug and formulation-specific data along with preclinical and clinical data for 83 
APIs, 43 of which were selected to be simulated in a large-scale performance evaluation of current state of the art in silico PBPK modelling platforms (see section 2.1 for selection criteria). This large-scale evaluation of current PBPK absorption models was seen as a first step toward identifying the strengths and weakness of current modelling software and approaches, and to guide further model development. Here we focus on the setup of this simulation exercise which involved the evaluation of three established software packages, GISim (AstraZeneca, London, UK), Simcyp ${ }^{\circledR}$ Simulator (Certara, Sheffield, UK), and GastroPlus $^{\mathrm{TM}}$ (SimulationsPlus, Lancaster, CA), and we present an overview of the results.

\section{Methods}

\subsection{API Selection}

As discussed in our companion paper, the APIs chosen for the simulation set were selected based on availability of information from a set of 83 compounds comprising the OrBiTo API database. The simulation set contained 43 APIs, and were chosen based on having the following minimum criteria: molecular weight, $\log \mathrm{P}$ or $\log \mathrm{D}$, at least one solubility point estimate or dissolution profile, in vitro permeability with reference compounds, any form of human in vitro clearance (e.g. measured in human liver microsomes, human hepatocytes, or recombinant CYP) or preclinical i.v. data (allowing for allometrically scaled clearance), and human fraction unbound in plasma (Margolskee et al. - Part 1 - Submitted). The 43 APIs chosen represented over 165 human studies, and approximately 600 clinical study arms. 


\subsection{API allocation}

Each API selected for this exercise was to be simulated by at least one institution in each of the three software packages. In order to test the impact of user differences, ten APIs (A0048, A1897, A2101, A3028, A3336, A3609, A4492, A6555, A9081, and A9606) were chosen to be simulated four times by different institutions in each of $\operatorname{SimCYP}^{\circledR}$ and GastroPlus ${ }^{\mathrm{TM}}$. Due to restricted availability of GI-Sim to participating institutions, each API could only be simulated once in this software package. Additionally, one API (A2733) was chosen to be simulated by all participating institutions in each software package available to them.

Each EFPIA partner was asked to randomly select API-software combinations to fulfil their resource allocation, while ensuring not to choose an API belonging to their own portfolio, in order to avoid introducing any unwelcomed bias that could arise from knowing the outcomes of the clinical trials. The remaining API-software combinations were distributed evenly among the academic institutions and commercial enterprises.

\subsection{Simulation procedure}

Each participating institution was asked to generate bottom-up predictions for every human study arm associated with their allocated APIs. Modellers were asked to simulate both population representative simulations as well as simulated trials (for GastroPlus and SimCYP) for each study arm. The simulated trials were set up using healthy volunteer populations built into the programs. The geometric mean age, height and weight of the observed trial were used to set both the population representative simulations and the simulated trial. The number of subjects for the simulated trials was set to match the observed trials. The modellers were asked to document their process through performing the simulations along with their selections for input parameters and simulation options. The modelling and simulation documentation and simulation output files coming directly from the 
software programs were uploaded and frozen on a shared space for analysis. After simulation output upload was complete, the observed PK human data were unblinded in the OrBiTo database to allow for the analysis of predicted vs measured data.

Overall guidance was drafted on how to handle the estimation of any missing parameters allowed in the simulation set. For example, when blood-to-plasma ratio (BP) was missing, it was suggested to be taken as 1 for netural and basic compounds, and 0.55 for acidic compounds. For allometric scaling of clearance, the recommended methods were the two best performing methods from Poulin et al. 2011 (referred to by them as TS_rat-dog and FCIM) or simple allometry. Due to lack of data on renal clearance, it was recommended at a minimum to use the fraction unbound times the glomerular filtration rate. For in vitro clearance data that were missing the unbound concentration in the incubation, it was recommended to use one of the various available estimation models (e.g. Austin et al. 2002, Halifax and Houston 2006; Turner et al. 2006).

However, due to the diversity of the parameters describing the APIs and how the in vitro data was obtained (in many cases data from multiple methods were available) along with software differences, it was decided against establishing standard operating procedures (SOPs) for selection and calculation of input parameters at the advantage of allowing the assessment of user differences between modellers and institutions. However, SimCYP and GI-Sim did create SOPs for entering the information into their software platforms, once the choice input parameters were decided upon. An overlap in the simulation study design between software platforms and modellers was implemented, giving the unique opportunity to enable the assessment of user and software differences in prediction success. 


\subsection{Data Collection}

Automated extraction of input options, as selected by modellers, was carried out using Matlab $^{\text {TM }}$ R2013a (Mathworks, Natick, MA). Input options that were not available from simulation output files were manually recorded by modellers in Microsoft Excel ${ }^{\circledR}, 2010$ (Microsoft, Redmond, WA). Following the completion of the simulation exercise, simulated plasma concentration-time profiles were extracted from simulation output files using Matlab and transferred into MS Excel templates which contained automated calculation of pharmacokinetic $(\mathrm{PK})$ parameters. Following the unblinding of the clinical data, observed plasma concentration-time profiles were treated in the same manner as the simulated profiles.

\subsection{Parameter Calculations}

Quality indicators for the evaluation of prediction success were selected prior to the simulation exercise based on metrics used in the literature, specific to PK predictions. The common practice in the PK community is the comparison of predicted vs. observed pharmacokinetic parameters, such as: the area under the curve (AUC), the maximum concentration $\left(\mathrm{C}_{\max }\right)$ and half-life (Poulin et al., 2011b; Van den Bergh et al., 2011; Sjogren et al., 2013), as well as direct comparison of predicted vs. observed plasma concentration time profiles. 
Table 1. Pharmacokinetic parameters to be evaluated.

\begin{tabular}{|c|c|c|c|c|}
\hline $\begin{array}{l}\text { All } \\
\text { formulations }\end{array}$ & $\begin{array}{l}\text { Oral } \\
\text { formulations }\end{array}$ & $\begin{array}{l}\text { i.v. } \\
\text { formulations }\end{array}$ & $\begin{array}{l}\text { Oral \& } \\
\text { i.v. }\end{array}$ & $\begin{array}{l}\text { Combinations of studies } \\
\text { and formulations }\end{array}$ \\
\hline $\begin{array}{l}\mathrm{AUC}_{0-\text { Tlast }} \\
\mathrm{AUC}_{0-\mathrm{Inf}} \\
\mathrm{C}_{\max } \\
\mathrm{T}_{\max } \\
\mathrm{T}_{1 / 2}\end{array}$ & $\begin{array}{l}\text { CL/F } \\
\mathrm{V}_{\mathrm{d}} / \mathrm{F} \\
\mathrm{MTT}\end{array}$ & $\begin{array}{l}\text { CL } \\
\mathrm{V}_{\mathrm{d}} \\
\text { MRT }\end{array}$ & $\begin{array}{l}\text { Foral }_{\text {oT }} \\
\text { MAT }\end{array}$ & $\begin{array}{l}\text { Relative } \mathrm{F} \\
\text { Relative } \mathrm{C}_{\max } \\
\text { Relative AUC }\end{array}$ \\
\hline \multicolumn{5}{|c|}{$\begin{array}{l}\mathrm{AUC}_{0 \text {-Tlast }}=\text { Area under the curve from time zero to last measured time point, } \mathrm{AUC}_{0 \text {-Inf }}=\mathrm{Area} \\
\text { under the curve from time zero extrapolated to infinity, } \mathrm{C}_{\max }=\text { Maximum concentration, } \mathrm{CL}= \\
\text { Clearance, } \mathrm{F}=\text { bioavailability, Foral = oral bioavailability, i.v. }=\text { intravenous, MAT }=\text { Mean } \\
\text { absorption time, MRT = Mean residence time, MTT = Mean transit time, } \mathrm{t}_{\max }=\text { Time of peak } \\
\text { concentration, } \mathrm{V}_{\mathrm{d}}=\text { Volume of distribution }\end{array}$} \\
\hline
\end{tabular}

Table 1 lists different PK parameters of interest, for different formulations, oral and i.v. study arms, and combinations of study arms and formulations. Each of the parameters for individual study arms was calculated for the observed plasma concentration profiles as well as the predicted profiles, using the same time points as the observed data.

Individual profiles, where available, were used to calculate all PK parameters, and the central tendency and deviation (Geometric Mean \& SD) of these parameters were calculated for each particular study arm. This method of estimating the PK parameters was applied to all simulated trials, population representative simulations, as well as all observed study arms for which individual data were supplied. For observed study arms which did not report individual data, PK parameters were calculated on the mean profile, and compared with PK parameters calculated on the mean profile of simulated trials. 
Table 2: Pharmacokinetic (PK) Parameter calculations

\begin{tabular}{|c|c|c|}
\hline Name & Symbol & Calculation \\
\hline $\begin{array}{l}\text { Area under the curve from } \\
\text { zero to the last time point }\end{array}$ & $\mathrm{AUC}_{0-\mathrm{t}, \text { last }}$ & $\frac{1}{2}\left(C\left(t_{i+1}\right)+C\left(t_{i}\right)\right) \cdot\left(t_{i+1}-t_{i}\right)$ \\
\hline $\begin{array}{l}\text { Area under the curve from } \\
\text { zero to infinity }\end{array}$ & $\overline{\mathrm{AUC}_{0 \text {-inf }}}$ & $A U C_{0-t_{\text {last }}}+\frac{C\left(t_{\text {last }}\right)}{k}$ \\
\hline $\begin{array}{l}\text { Maximum plasma } \\
\text { concentration }\end{array}$ & $\mathrm{C}_{\max }$ & $\operatorname{ax}\left(C\left(t_{i}\right)\right)$ over all $t_{i}$ \\
\hline $\begin{array}{l}\text { Time at maximum } \\
\text { concentration }\end{array}$ & $\mathrm{T}_{\max }$ & $t_{i}$ such that $C\left(t_{i}\right)=C_{\max }$ \\
\hline Half life & $\mathrm{T}_{1 / 2}$ & $\frac{\ln (2)}{k}$ \\
\hline $\begin{array}{l}\text { Clearance or apparent oral } \\
\text { clearance }\end{array}$ & $\mathrm{CL}$ or $\mathrm{CL} / \mathrm{F}$ & $\frac{\text { Dose }}{A U C_{0-\operatorname{Inf}}}$ \\
\hline $\begin{array}{l}\text { Volume of distribution or } \\
\text { apparent oral volume of } \\
\text { distribution }\end{array}$ & $\mathrm{V}_{\mathrm{d}}$ or $\mathrm{V}_{\mathrm{d}} / \mathrm{F}$ & $\frac{C L \text { or } C L / F}{k}$ \\
\hline $\begin{array}{l}\text { Area under the moment } \\
\text { curve from zero to last time } \\
\text { point }\end{array}$ & $\mathrm{AUMC}_{0-\mathrm{t}, \text { last }}$ & $\sum_{i=0}^{N} \frac{1}{2}\left(t_{i+1} C\left(t_{i+1}\right)+t_{i} C\left(t_{i}\right)\right) \cdot\left(t_{i+1}-t_{i}\right)$ \\
\hline $\begin{array}{l}\text { Area under the moment } \\
\text { curve from zero to infinity }\end{array}$ & $\mathrm{AUMC}_{0 \text {-inf }}$ & $A U M C_{0-t_{\text {last }}}+\frac{C\left(t_{\text {last }}\right)}{k}\left(t_{\text {last }}+\frac{1}{k}\right)$ \\
\hline $\begin{array}{l}\text { Mean residence time (for } \\
\text { i.v. profiles) or mean transit } \\
\text { time (for oral profiles) }\end{array}$ & MRT or MTT & $\frac{A U M C_{0-i n f}}{A U C_{0-i n f}}$ \\
\hline \multicolumn{3}{|c|}{$\begin{array}{l}\mathrm{C}(\mathrm{t})=\text { plasma concentration at time } \mathrm{t} \\
\mathrm{t}_{\text {last }}=\text { last observed time point } \\
\mathrm{k}=\text { terminal exponential decay rate estimated from an exponential fit }\left(\mathrm{C}(\mathrm{t})=\mathrm{A} \mathrm{e}^{-\mathrm{kt}}\right) \text { to the terminal } \\
\text { plasma concentration profile following the adjusted } \mathrm{R} \text { squared algorithm as detailed in Phoenix } \\
\text { WinNonlin (Pharsight Corporation, } \mathrm{CA} \text { ). }\end{array}$} \\
\hline
\end{tabular}

\subsection{Summary Statistics}

The performance of the models to predict the PK parameters can be evaluated through different metrics such as Average Fold and Root Mean Squared Errors (Van den Bergh et al., 2011), as well as Absolute Average Fold Errors and correlation and Concordance Correlation 
Coefficients (Poulin et al., 2011a). Each of these metrics provides a different measure for the prediction, each with its own interpretation, and provides a different perspective on the performance of the simulations. For example the percent of predictions within a certain fold error provides a measure of accuracy (i.e. the magnitude of the deviation from observed)

while the average fold error measures the bias of the predictions (i.e. the central tendency of the deviation). Table 3 lists the metrics that were applied to analyse the success of prediction of PK parameters.

Table 3: Metrics for evaluating success of predictions

\begin{tabular}{|c|c|c|c|c|}
\hline Name & Symbol & Formula & Description & References \\
\hline $\begin{array}{l}\% \text { within } 2-, 3- \\
, 10 \text {-fold error }\end{array}$ & & $\begin{array}{r}\text { freq }\left(\max \left(\frac{\text { Pred }_{i}}{\text { Obs }_{i}}, \frac{\text { Obs }_{i}}{\text { Pred }_{i}}\right)\right. \\
<2,3,10)\end{array}$ & $\begin{array}{l}\text { Gives an idea of the magnitude } \\
\text { of the error; however meaningful } \\
\text { cut-offs have not been rigorously } \\
\text { defined. }\end{array}$ & $\begin{array}{l}\text { (Takamatsu } \\
\text { et al., 2001; } \\
\text { Rodgers et } \\
\text { al., 2005; } \\
\text { Poulin et al., } \\
\text { 2011a; Van } \\
\text { den Bergh et } \\
\text { al., 2011) }\end{array}$ \\
\hline $\begin{array}{l}\text { Average fold } \\
\text { error }\end{array}$ & AFE & 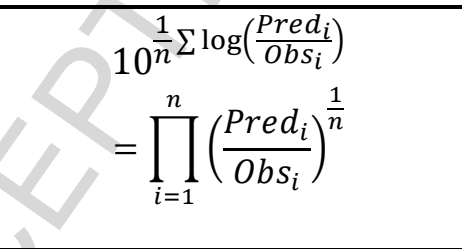 & $\begin{array}{l}\text { With the AFE, underpredictions } \\
\text { and overpredictions cancel each } \\
\text { other out, resulting in a measure } \\
\text { of bias only. }\end{array}$ & $\begin{array}{l}\text { (Takamatsu } \\
\text { et al., 2001; } \\
\text { Poulin et al., } \\
\text { 2011a; Van } \\
\text { den Bergh et } \\
\text { al., 2011) }\end{array}$ \\
\hline $\begin{array}{l}\text { Absolute } \\
\text { average fold } \\
\text { error }\end{array}$ & & $\begin{array}{c}10^{\frac{1}{n} \sum\left|\log \left(\frac{\text { Pred }_{i}}{\text { Obs }_{i}}\right)\right|} \\
=\prod_{i=1}^{n}\left(\max \left(\frac{\text { Pred }_{i}}{\text { Obs }_{i}}, \frac{\text { Obs }_{i}}{\text { Pred }_{i}}\right)\right)^{\frac{1}{n}}\end{array}$ & $\begin{array}{l}\text { The AAFE converts negative log } \\
\text { fold errors to positive values } \\
\text { before averaging, measuring the } \\
\text { spread of the predictions. }\end{array}$ & $\begin{array}{l}\text { (Takamatsu } \\
\text { et al., 2001; } \\
\text { Poulin et al., } \\
\text { 2011a) }\end{array}$ \\
\hline $\begin{array}{l}\text { Root mean } \\
\text { squared log } \\
\text { error }\end{array}$ & RMSLE & $\begin{array}{c}\sqrt{\frac{1}{n} \sum\left(\log \left(\text { Pred }_{i}\right)-\log \left(\text { Obs }_{i}\right)\right)^{2}} \\
\quad=\sqrt{\frac{1}{n} \sum\left(\log \left(\frac{\text { Pred }_{i}}{\text { Obs }_{i}}\right)\right)^{2}}\end{array}$ & $\begin{array}{l}\text { The RMSLE combines the } \\
\text { variance and bias of an } \\
\text { estimator. For an unbiased } \\
\text { estimator, the RMSLE } \\
\text { represents the standard deviation } \\
\text { between the predicted and } \\
\text { observed log data. }\end{array}$ & $\begin{array}{l}\text { (Takamatsu } \\
\text { et al., 2001) }\end{array}$ \\
\hline $\begin{array}{l}\text { Correlation } \\
\text { coefficient }\end{array}$ & $\overline{\mathrm{R}}$ & $\frac{s_{x y}}{\sqrt{s_{x}^{2} s_{y}^{2}}}$ & $\begin{array}{l}\text { A measure of the degree of } \\
\text { linear relationship between } \\
\text { predicted and observed data. }\end{array}$ & $\begin{array}{l}\text { (Poulin et al., } \\
\text { 2011b) }\end{array}$ \\
\hline $\begin{array}{l}\text { Concordance } \\
\text { correlation } \\
\text { coefficient }\end{array}$ & $\mathrm{CCC}$ & $\begin{array}{l}\frac{2 s_{x y}}{s_{x}^{2}+s_{y}^{2}+(\bar{x}-\bar{y})^{2}} \\
\text { Where } \\
\qquad s_{x y}=\frac{1}{n} \sum\left(x_{i}-\bar{x}\right)\left(y_{i}-\bar{y}\right) \\
\qquad s_{x}^{2}=\frac{1}{n} \sum\left(x_{i}-\bar{x}\right)^{2}\end{array}$ & $\begin{array}{l}\text { The CCC is a measure of the } \\
\text { degree of } 1 \text {-to- } 1 \text { correlation } \\
\text { between predicted and observed } \\
\text { data. It is based on the } \\
\text { perpendicular deviation from the } \\
45 \text { degree line. }\end{array}$ & $\begin{array}{l}\text { (Takamatsu } \\
\text { et al., 2001; } \\
\text { Winiwarter et } \\
\text { al., 2003) }\end{array}$ \\
\hline
\end{tabular}






\section{Results and Discussion}

\subsection{Overview}

By the end of the simulation exercise, an endeavour set to last six months, over 4,000 simulation files had been generated by the participating institutions, representing over 2,550 study arm-institution-software combinations. Table 4 displays the breakdown of contribution by partner, detailing the number of study arms and APIs simulated in each software package. Figure 3 shows boxplots for fold error in $\mathrm{AUC}_{0-\mathrm{t}, \text { last }}$ and $\mathrm{C}_{\max }$ predictions for all single dose, fasted state, i.v. and p.o. simulations, grouped by institution, institution type, modeller experience, and software package.

Table 4: Breakdown of contributed simulations by partner.

\begin{tabular}{|c|c|c|c|c|c|c|c|c|}
\hline & \multicolumn{4}{|c|}{ Number of study arms simulated } & \multicolumn{4}{|c|}{ Number of APIs simulated } \\
\hline & $\begin{array}{l}\text { Total software- } \\
\text { study arm } \\
\text { combinations }\end{array}$ & $\begin{array}{l}\text { In } \\
\text { GastroPlus }\end{array}$ & $\begin{array}{l}\text { In } \\
\text { SimCYP }\end{array}$ & $\begin{array}{l}\text { In GI- } \\
\text { Sim }\end{array}$ & $\begin{array}{l}\text { Total } \\
\text { software-API } \\
\text { combinations }\end{array}$ & $\begin{array}{l}\text { In } \\
\text { GastroPlus }\end{array}$ & $\begin{array}{l}\text { In } \\
\text { SimCYP }\end{array}$ & $\begin{array}{l}\text { In GI- } \\
\text { Sim }\end{array}$ \\
\hline UNIMAN & 576 & 163 & 151 & 262 & 42 & 13 & 13 & 16 \\
\hline AstraZeneca & 249 & 53 & 54 & 142 & 24 & 5 & 5 & 14 \\
\hline Sanofi & 234 & 94 & 140 & 0 & 15 & 7 & 8 & 0 \\
\hline SimCYP & 221 & 0 & 221 & 0 & 20 & 0 & 20 & 0 \\
\hline Orion & 216 & 216 & 0 & 0 & 16 & 16 & 0 & 0 \\
\hline UGoethe & 198 & 79 & 78 & 41 & 17 & 6 & 6 & 5 \\
\hline Novartis & 197 & 99 & 98 & 0 & 14 & 7 & 7 & 0 \\
\hline AbbVie & 160 & 80 & 80 & 0 & 10 & 5 & 5 & 0 \\
\hline SimulationsPlus & 121 & 121 & 0 & 0 & 11 & 11 & 0 & 0 \\
\hline Pfizer & 99 & 70 & 29 & 0 & 7 & 5 & 2 & 0 \\
\hline Merck & 88 & 44 & 44 & 0 & 8 & 4 & 4 & 0 \\
\hline Janssen & 85 & 41 & 44 & 0 & 6 & 3 & 3 & 0 \\
\hline GSK & 72 & 36 & 36 & 0 & 8 & 4 & 4 & 0 \\
\hline UMainz & 38 & 19 & 19 & 0 & 4 & 2 & 2 & 0 \\
\hline BMS & 2 & 2 & 0 & 0 & 1 & 1 & 0 & 0 \\
\hline
\end{tabular}


Average prediction performance was consistent across the three different institution types (Figure 3C-D), indicating no institution type performed better on average than the others. However, noticeably higher variability in fold error was observed for academia. This could be related to the level of experience of these modellers as this group tended to have less experience. While average prediction performance appeared to be consistent across different levels of experience, an increase in variability was displayed for modellers with less than 5 years of experience (Figure 3E-F).

In the context of this simulation exercise, each of industry, small-medium enterprises (SMEs) and academic partners had the same level of access to information and familiarity with the pharmaceutics in question, a fact that was facilitated by the blinded nature of the exercise. In practice, these considerations could potentially give rise to a greater difference in performance outcome.

Within each API, variability was observed across different modelling groups and software package utilised. The largest discrepancy observed across the three software packages was for API A8791 where the fold difference between SimCYP and GI-Sim predicted AFEs in $\mathrm{AUC}_{0-\mathrm{t}, \text { last }}$ predictions was 606-fold, followed by A0799 with 171 fold difference, and A0633 with 81.7 fold difference between SimCYP and GI-Sim predictions (Figure 4A; Table 5). These three APIs followed the same trend in $\mathrm{C}_{\max }$ predictions with 593, 87.2, and 60.5-fold difference between SimCYP and GI-Sim predicted AFEs in $\mathrm{C}_{\max }$ (Figure 4B; Table 6). While 
considerable software differences in $\mathrm{AUC}_{0-\mathrm{t}, \text { last }}$ predictions were observed for some APIs, the average prediction performance was relatively consistent across the three different software platforms evaluated in this exercise $\left(\mathrm{AUC}_{0-\mathrm{t}, \text { last }} \mathrm{AFE}\right.$ of $1.52,1.32$, and 0.992 for GastroPlus, SimCYP, and GI-Sim, respectively; Figure 3G).

The limited availability of information to inform the models, as well as limited complexity in that information could be masking potential differences in performance that level of experience or software package choice could have provided. As was discussed in the companion paper, the OrBiTo database and the simulation set of APIs expressed a high level of missing certain information (e.g. solubility in biorelevant media, dissolution and precipitation rates, in vivo preclinical $\mathrm{PK}$ ), as well as a relatively limited complexity in formulations (only $7.1 \%, 1.6 \%$ and $0.5 \%$ of the administered formulations in the database represented prolonged release, delayed release, and colon targeted formulations, respectively) (Margolskee et al. - Part 1-Submitted).

Figure $3 \mathrm{~A}$ displays the fold error in $\mathrm{AUC}_{0-\mathrm{t}, \text { last }}$ predictions grouped by institution. The average prediction performance was fairly consistent across the different institutions, with a few deviations (e.g. institutions 9, 12, 13, 14). Within institution $\mathrm{AUC}_{0-\text { t,last }} \mathrm{AFE}$ ranged from 0.148 (or 6.77-fold underprediction; institution 13) to 3.67-fold overprediction (institution 12) while $C_{\max }$ AFE ranged from 0.129 (7.73-fold underprediction; institution 13) to 2.58fold overprediction (institution 3). Further exploration of these differences may help to inform standard procedures in PBPK modelling approaches. 
Figure 4 shows the overall $\mathrm{FE}$ in $\mathrm{AUC}_{0-\mathrm{t}, \text { last }}$ predictions for all single dose, fasted state, i.v. and p.o. simulations, grouped by API. On average, the observed $\mathrm{AUC}_{0-\mathrm{t} \text {,last }}$ values were slightly overpredicted, with a median $\mathrm{FE}$ for $\mathrm{AUC}_{0-\mathrm{t}, \text { last }}$ of 1.56 over all of the simulations, while median $\mathrm{FE}$ for $\mathrm{C}_{\max }$ was slightly underpredicted at 0.875 (1.14-fold underprediction). The overall $5^{\text {th }}$ and $95^{\text {th }}$ percentiles of $\mathrm{FE}$ in $\mathrm{AUC}_{0-\mathrm{t}, \text { last }}$ prediction were 0.0283 -fold (representing a 35.3-fold underprediction) and 21.6-fold, respectively. For $\mathrm{C}_{\max }$, the $5^{\text {th }}$ and $95^{\text {th }}$ percentiles of FE were 0.0183 (54.6-fold underprediction) and 7.58-fold overprediction. 25 of the 43 APIs showed overpredictions in $\mathrm{AUC}_{0-\mathrm{t}, \text { last }}$ on average (AFE > 1), while only 15 showed overpredictions in $\mathrm{C}_{\max }$. Prediction performance showed a high between API variability, with $\mathrm{AUC}_{0 \text {-t,last }} \mathrm{AFE}$ ranging from 0.0361 (or 27.7-fold underprediction) to 64.0fold overprediction, and $\mathrm{C}_{\max } \mathrm{AFE}$ ranging from 0.0235 (or 42.6-fold underprediction) to 4.54-fold overprediction (Figure 4). 
A

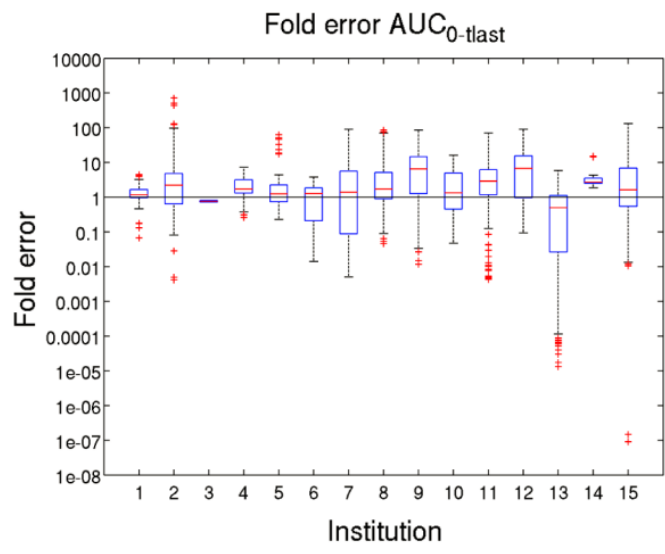

C



E

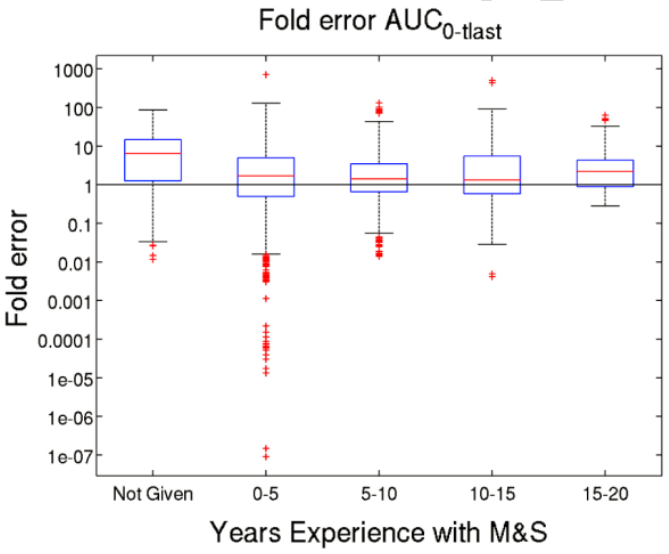

G

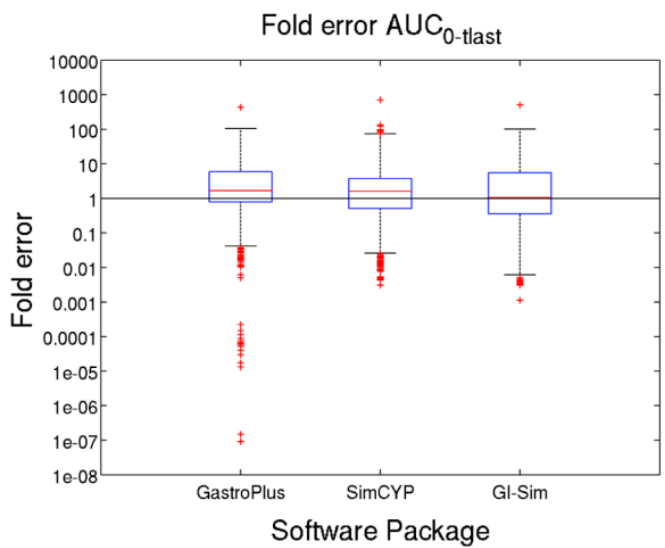

B



D

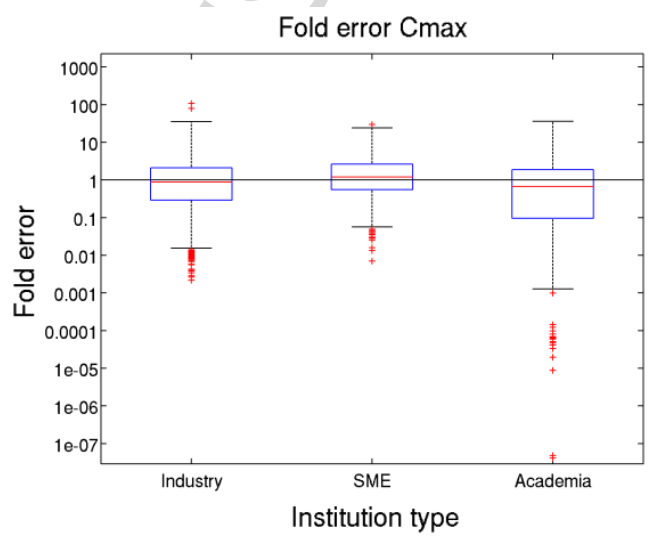

F

Fold error $\mathrm{C} \max$

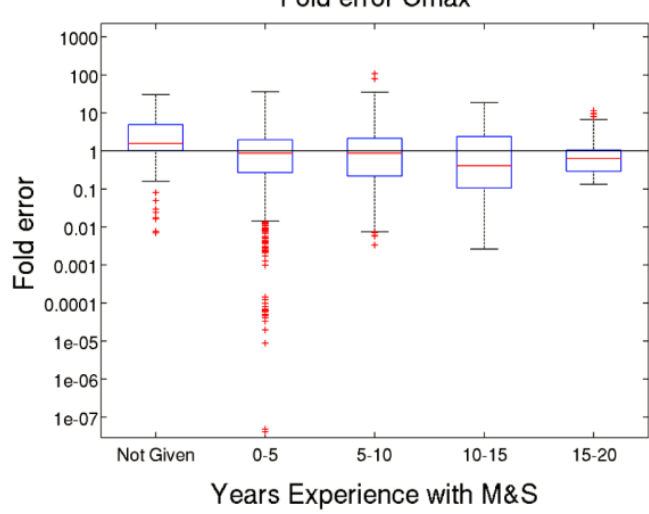

H

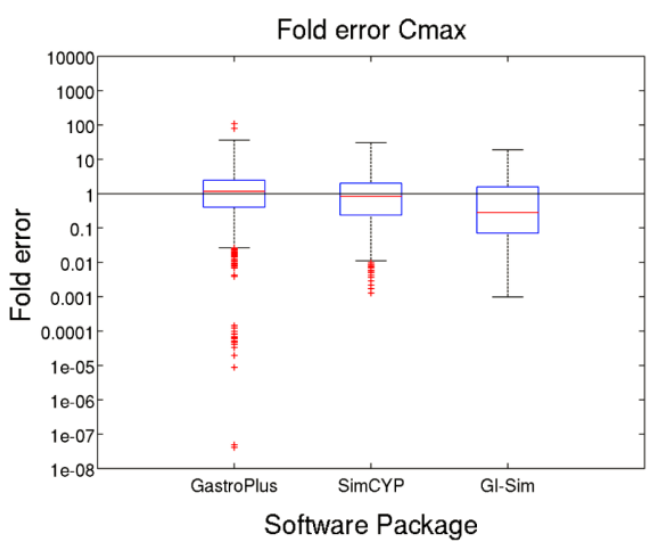


Figure 3: Boxplots for the fold error in $\mathrm{AUC}_{0-\mathrm{t}, \text { last }}$ (left panels) and $\mathrm{C}_{\max }$ (right panels) predictions for each studyarm-institution-software combination, grouped by A-B: institution (numbered 1 through 15), C-D: Institution type (industry, small-medium enterprise (SME), or academia), E-F: years' experience with modelling and simulation (M\&S), and G-H: software package. 
A

Fold error $\mathrm{AUC}_{\text {0-tlast }}$

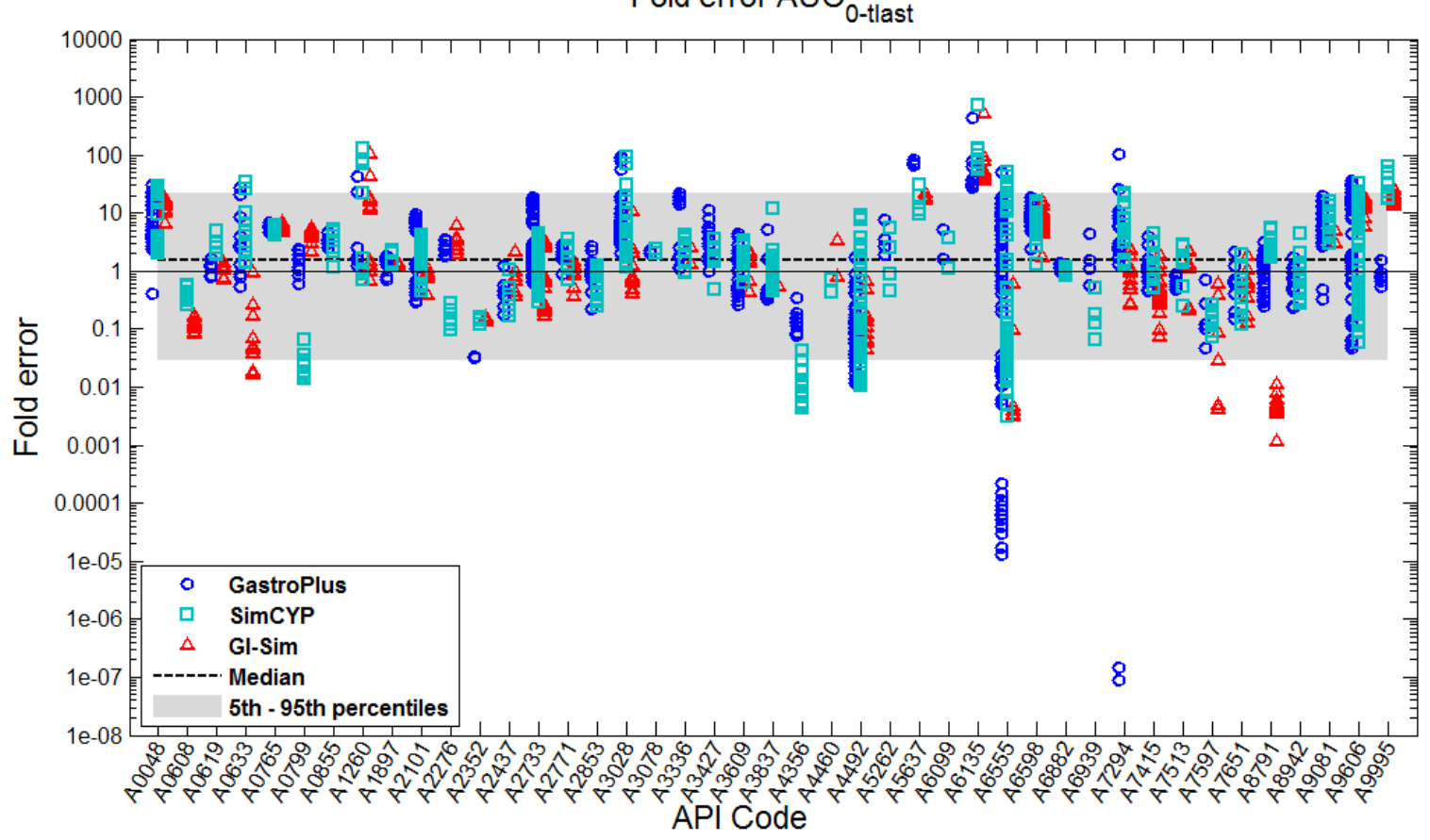

B

Fold error Cmax



Figure 4. Fold error in $\mathbf{A}: \mathrm{AUC}_{0-\mathrm{t}, \text { last }}$ and $\mathbf{B}: \mathrm{C}_{\max }$ predictions for each simulation generated in

GastroPlus (blue circles), SimCYP (cyan squares) and GI-Sim (red triangles), grouped by

API, along with the overall $5^{\text {th }}$ and $95^{\text {th }}$ percentile interval (grey region) and overall median (black dashed line). 
Table 5: Average fold error $(\mathrm{AFE})$ in $\mathrm{AUC}_{0-\mathrm{t}, \text { last }}$ predictions for each API overall and in each software package

\begin{tabular}{|c|c|c|c|c|}
\hline APIcode & Overall AFE & GastroPlus AFE & SimCYP AFE & GI-Sim AFE \\
\hline A0048 & 6.7543 & 6.8319 & 5.3956 & 12.6761 \\
\hline A0608 & 0.2219 & & 0.3787 & 0.1225 \\
\hline A0619 & 1.4222 & 1.1453 & 2.7476 & 1.0044 \\
\hline A0633 & 0.9903 & 3.0249 & 5.1218 & 0.0627 \\
\hline A0765 & 5.3576 & 5.5983 & 4.9872 & 5.5083 \\
\hline A0799 & 0.4961 & 1.3229 & 0.0232 & 3.9777 \\
\hline $\mathbf{A 0 8 5 5}$ & 3.1253 & 3.2876 & 2.9711 & \\
\hline A1260 & 5.8776 & 3.7359 & 8.1481 & 5.8274 \\
\hline A1897 & 1.4291 & 1.3449 & 1.7175 & 1.3405 \\
\hline A2101 & 2.1308 & 2.9359 & 1.9341 & 0.7907 \\
\hline A2276 & 1.0551 & 2.5185 & 0.1455 & 3.2061 \\
\hline A2352 & 0.0902 & 0.0333 & 0.1452 & 0.1518 \\
\hline A2437 & 0.4488 & 0.3849 & 0.3387 & 0.6935 \\
\hline A2733 & 1.6738 & 2.079 & 1.5741 & 0.8235 \\
\hline A2771 & 1.519 & 1.8844 & 2.0469 & 0.9087 \\
\hline A2853 & 0.8215 & 0.9945 & 0.6651 & \\
\hline A3028 & 4.7808 & 6.8915 & 4.629 & 1.0741 \\
\hline A3078 & 2.1982 & 2.1429 & 2.2549 & \\
\hline A3336 & 3.8644 & 6.4545 & 2.5162 & 1.6538 \\
\hline A3427 & 2.5545 & 3.1029 & 1.6377 & \\
\hline A3609 & 1.1578 & 0.8301 & 1.7782 & 1.2095 \\
\hline A3837 & 0.8262 & 0.5465 & 1.104 & 0.5367 \\
\hline A4356 & 0.0361 & 0.1285 & 0.0101 & \\
\hline A4460 & 0.9534 & & 0.5616 & 1.6185 \\
\hline A4492 & 0.1353 & 0.0967 & 0.1995 & 0.1254 \\
\hline A5262 & 2.3306 & 3.4974 & 1.5531 & \\
\hline A5637 & 27.9434 & 73.6427 & 15.9327 & 18.5959 \\
\hline A6099 & 2.4249 & 2.9093 & 2.0211 & \\
\hline A6135 & 63.9694 & 46.1723 & 93.9698 & 60.3319 \\
\hline A6555 & 0.1391 & 0.1558 & 0.1674 & 0.0104 \\
\hline A6598 & 7.2007 & 8.4175 & 6.1509 & 7.2489 \\
\hline A6882 & 1.0778 & 1.1835 & 0.9815 & \\
\hline A6939 & 0.4958 & 1.4499 & 0.1695 & \\
\hline A7294 & 1.381 & 0.6496 & 5.4808 & 0.7397 \\
\hline A7415 & 0.7766 & 1.0422 & 1.1228 & 0.4003 \\
\hline A7513 & 0.8864 & 0.6733 & 1.1876 & 0.8709 \\
\hline A7597 & 0.1138 & 0.1752 & 0.1574 & 0.0479 \\
\hline A7651 & 0.5155 & 0.5853 & 0.4681 & 0.5088 \\
\hline A8791 & 0.5038 & 0.9736 & 2.6648 & 0.0044 \\
\hline
\end{tabular}




\begin{tabular}{|l|r|r|r|r|}
\hline $\mathbf{A 8 9 4 2}$ & 0.7461 & 0.6338 & 0.8615 & \\
\hline $\mathbf{A 9 0 8 1}$ & 6.0196 & 6.1116 & 6.1725 & 3.847 \\
\hline $\mathbf{A 9 6 0 6}$ & 3.636 & 4.3199 & 2.3232 & 13.0719 \\
\hline $\mathbf{A 9 9 9 5}$ & 8.0456 & 0.8038 & 34.0971 & 19.0014 \\
\hline
\end{tabular}

Table 6: Average fold error (AFE) in $\mathrm{C}_{\max }$ predictions for each API overall and in each software package

\begin{tabular}{|l|r|r|r|r|}
\hline APIcode & Overall AFE & GastroPlus AFE & SimCYP AFE & GI-Sim AFE \\
\hline A0048 & 2.0674 & 2.139 & 1.431 & 5.264 \\
\hline $\mathbf{A 0 6 0 8}$ & 0.04473 & & 0.1421 & 0.01254 \\
\hline $\mathbf{A 0 6 1 9}$ & 1.554 & 3.558 & 3.191 & 0.3613 \\
\hline $\mathbf{A 0 6 3 3}$ & 0.5058 & 1.331 & 2.525 & 0.0417 \\
\hline $\mathbf{A 0 7 6 5}$ & 0.9810 & 1.126 & 0.9203 & 0.9113 \\
\hline $\mathbf{A 0 7 9 9}$ & 0.5855 & 3.507 & 0.04024 & 1.422 \\
\hline $\mathbf{A 0 8 5 5}$ & 0.6337 & 0.8254 & 0.4865 & \\
\hline $\mathbf{A 1 2 6 0}$ & 0.1344 & 0.3212 & 0.1952 & 0.05082 \\
\hline $\mathbf{A 1 8 9 7}$ & 2.929 & 3.250 & 2.956 & 1.708 \\
\hline $\mathbf{A 2 1 0 1}$ & 0.7184 & 0.9099 & 0.8518 & 0.1674 \\
\hline $\mathbf{A 2 2 7 6}$ & 0.6693 & 2.608 & 0.1945 & 0.5910 \\
\hline $\mathbf{A 2 3 5 2}$ & 0.02611 & 0.02454 & 0.02614 & 0.02774 \\
\hline $\mathbf{A 2 4 3 7}$ & 0.6479 & 1.250 & 0.3486 & 0.6239 \\
\hline $\mathbf{A 2 7 3 3}$ & 0.8034 & 0.9812 & 0.8973 & 0.2113 \\
\hline $\mathbf{A 2 7 7 1}$ & 0.9234 & 1.120 & 1.023 & 0.6871 \\
\hline $\mathbf{A 2 8 5 3}$ & 0.7228 & 0.7161 & 0.7302 & \\
\hline $\mathbf{A 3 0 2 8}$ & 1.870 & 3.304 & 1.502 & 0.3317 \\
\hline $\mathbf{A 3 0 7 8}$ & 0.3758 & 0.2966 & 0.4762 & \\
\hline $\mathbf{A 3 3 3 6}$ & 0.5083 & 1.007 & 0.2907 & 0.2563 \\
\hline $\mathbf{A 3 4 2 7}$ & 2.123 & 3.370 & 0.7600 & \\
\hline $\mathbf{A 3 6 0 9}$ & 0.8739 & 0.8417 & 1.268 & 0.3325 \\
\hline $\mathbf{A 3 8 3 7}$ & 2.149 & 2.162 & 2.141 & 2.155 \\
\hline $\mathbf{A 4 3 5 6}$ & 0.2031 & 0.7702 & 0.05354 & \\
\hline $\mathbf{A 4 4 6 0}$ & 1.120 & & 0.4950 & 2.536 \\
\hline $\mathbf{A 4 4 9 2}$ & 0.1574 & 0.1282 & 0.1726 & 0.2501 \\
\hline $\mathbf{A 5 2 6 2}$ & 0.9425 & 1.063 & 0.8355 & \\
\hline $\mathbf{A 5 6 3 7}$ & 1.442 & 2.729 & 1.432 & 0.7672 \\
\hline $\mathbf{A 6 0 9 9}$ & 2.752 & 3.136 & 2.415 & \\
\hline $\mathbf{A 6 1 3 5}$ & 4.537 & 4.046 & 4.327 & 5.387 \\
\hline $\mathbf{A 6 5 5 5}$ & 0.06320 & 0.07080 & 0.06880 & 0.009279 \\
\hline $\mathbf{A 6 5 9 8}$ & 2.045 & 0.526 & 0.007500 & 0.8995 \\
\hline $\mathbf{A 6 8 8 2}$ & 0.02347 & & & \\
\hline $\mathbf{A 6 9 3 9}$ & & & & \\
\hline & & & & \\
\hline
\end{tabular}




\begin{tabular}{|l|r|r|r|r|}
\hline $\mathbf{A 7 2 9 4}$ & 0.1950 & 0.1044 & 1.002 & 0.07086 \\
\hline $\mathbf{A 7 4 1 5}$ & 0.2528 & 0.4711 & 0.3401 & 0.1009 \\
\hline $\mathbf{A 7 5 1 3}$ & 1.760 & 0.4121 & 4.002 & 3.306 \\
\hline $\mathbf{A 7 5 9 7}$ & 0.04496 & 0.05762 & 0.1036 & 0.01308 \\
\hline $\mathbf{A 7 6 5 1}$ & 0.1067 & 0.1006 & 0.1232 & 0.09692 \\
\hline $\mathbf{A 8 7 9 1}$ & 0.5090 & 0.9532 & 1.733 & 0.002921 \\
\hline $\mathbf{A 8 9 4 2}$ & 0.2549 & 0.1863 & 0.3329 & \\
\hline $\mathbf{A 9 0 8 1}$ & 2.639 & 2.713 & 2.605 & 1.246 \\
\hline $\mathbf{A 9 6 0 6}$ & 1.472 & 1.153 & 1.412 & 5.521 \\
\hline $\mathbf{A 9 9 9 5}$ & 3.910 & 0.9733 & 7.185 & 8.549 \\
\hline
\end{tabular}

\subsection{Observed vs. predicted regression lines}

In order to gauge the overall predictive performance of the OrBiTo simulations for each of the 43 APIs in the simulation set, predicted and observed, absolute and relative bioavailability, and $\mathrm{AUC}_{0 \text {-t,last }}$ averaged by geometric mean over the study arms for each API were examined (Figure 5; Table A4). For all oral simulations (n APIs = 43), the correlation between predicted and observed $\log 10\left(\mathrm{AUC}_{0-\mathrm{t}}\right)$ gave an $\mathrm{R}$ of 0.766 and a $\mathrm{CCC}$ of 0.759 (Figure 5A), or 0.103 and 0.0969 , respectively, for the linear scale. The examination of i.v. only simulations ( $\mathrm{n}$ APIs=17) gave slightly better regression coefficients (R: 0.908 and CCC: 0.870, or R: 0.500 and CCC: 0.438 for the linear scale) (Figure 5B). The overall trend in oral bioavailability $\left(\mathrm{F}_{\text {oral }}\right.$; APIs=17) showed lower correlations between predicted and observed, with an R of 0.346 and CCC of 0.345 (Figure 5C). However, these correlations were better than those for the linear scaled data for oral formulations. The overall ability to predict relative bioavailability between oral formulations and solutions gave an $\mathrm{R}$ of 0.443 and $\mathrm{CCC}$ of 0.389 between observed and predicted data (Figure 5D). For more information on the types of oral formulations available in the database, see our companion paper (Margolskee et al. Part 1 - Submitted). 
A



C

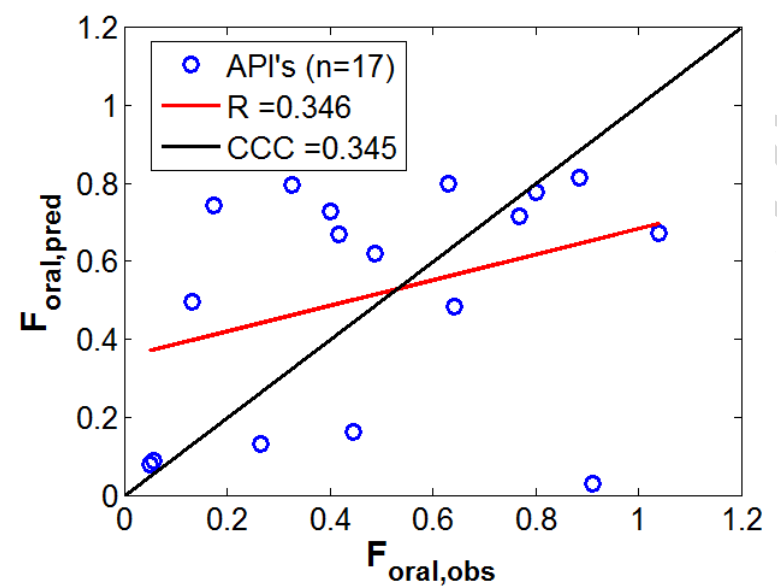

B



D



Figure 5: Overall predictive performance of the OrBiTo simulation dataset, displaying the geometric mean observed against predicted data for $\mathbf{A}: \log 10\left(\mathrm{AUC}_{0-\mathrm{t}, \text { last }}\right)$ for observed against predicted oral data only, B: $\log 10\left(\mathrm{AUC}_{0-\mathrm{t}, \mathrm{last}}\right)$ for observed against predicted i.v.data only, C: Observed vs. predicted oral bioavailability $\left(\mathrm{F}_{\text {oral }}\right), \mathbf{D}$ : Observed vs. predicted relative bioavailability $\left(\mathrm{F}_{\text {rel }}\right)$ for per oral formulations as compared to immediate-release formulations. $\mathrm{R}=$ Pearson regression coefficient, $\mathrm{CCC}=$ concordance correlation coefficient.

\subsection{Overview by different formulations}

A total of 594 human study arms were simulated by the different institutions, of which 445 were both single dose and in the fasted state. Of these 445 study arms, 22 had administered 
i.v. formulations, 376 immediate-release (IR) formulations, 32 prolonged release, 3 delayed release and 12 enterion coated (Table 7).

Table 7. Number of simulated study arms and APIs administering different formulations types.

\begin{tabular}{|l|r|r|}
\hline Formulation Type & Number of Study Arms & Number of APIs \\
\hline i.v. Bolus & 9 & 7 \\
\hline i.v. Infusion & 13 & 10 \\
\hline Solution & 131 & 28 \\
\hline IR Suspension & 29 & 10 \\
\hline IR Tablet & 102 & 31 \\
\hline IR Capsule & 100 & 16 \\
\hline IR Solid dispersion & 7 & 1 \\
\hline IR Nano-suspension & 7 & 1 \\
\hline Prolonged Release Tablet & 31 & 5 \\
\hline Prolonged Release Capsule & 1 & 1 \\
\hline Delayed release (time based) Capsule & 3 & 1 \\
\hline Enterion & 12 & 7 \\
\hline
\end{tabular}

Progressing from i.v. administration to oral solution, IR tablet and all p.o. formulations, there was a reduction in $\mathrm{AUC}_{0-\mathrm{t}, \text { last }}$ prediction performance as measured by percent within 2, 3, and 10-fold error and correlation coefficients, $\mathrm{R}$ and CCC. This is indicative of the compounding error that occurs with each layer of model complexity, highlighting the challenges of predicting oral bioavailability and the need for clinically informed i.v. disposition for the proper investigation of intestinal model performance. Examining the predictive performance of bioavailability can partially account for these confounding errors however $\mathrm{F}_{\text {oral }}$ calculations were limited to 17 APIs in the OrBiTo simulation dataset. Many of the APIs were lacking i.v. data; however, it was possible to compare relative bioavailability between oral formulations (Figure 6; Table A4). 
A general trend of overprediction of exposure was observed for p.o. and i.v. simulations as compared to observed data with a calculated AFE of 1.30 and 1.64, respectively (Figure 6B; Table A4). Overprediction for solutions was even higher with an AFE of 1.97. The variability in FEs was slightly higher for p.o. and solution simulations with AAFE above 3 (3.21 and 3.04) as compared with i.v. FEs, displaying an AAFE of 2.51. Similarly, a higher percentage of i.v. simulations were predicted to within two and three-fold $(52.9 \%$ and $70.6 \%)$ as compared with all p.o. simulations (37.2\% and 55.8\%; Figure 6A).

$\mathrm{F}_{\text {oral }}$ was generally well predicted, with $64.7 \%, 53.8 \%$ and $70.0 \%$ within two-fold for all p.o. formulations $(n=17)$, for IR tablets $(n=13)$, and solutions $(n=10)$, and displaying AFE of 1.00, 0.89 (a 1.12-fold underprediction), and 1.10 (Figure 6D and E; Table A4). However, poor correlation between observed and predicted was exhibited for bioavailability of solutions ( $\mathrm{R}$ 0.111; CCC -0.106) (Figure 6F).

The poor correlation between observed and predicted solution $\mathrm{F}_{\text {oral }}(\mathrm{R}-0.111$ and $\mathrm{CCC}$ 0.106; Figure 6F) raises some concerns about the consistency in predictions of permeation, as other formulations showed slightly better correlation between predicted and observed bioavailability (R 0.35 and 0.178 for p.o. and IR tablet, respectively), and $\mathrm{F}_{\text {rel }}$ between p.o. formulations and solution showed even greater improvement ( $\mathrm{R}$ of 0.44 and 0.6 for p.o. formulations and IR tablet; Figure 6I). One might expect the prediction of $F_{\text {oral }}$ for solutions to have better correlation than for other formulations since permeation is not generally thought to be as big of a hurdle to overcome as solubility. However, these results could be interpreted as permeability and first pass effects not being as well characterised, or the input parameters not as informative as those for solubility and dissolution. 
The focus of the OrBiTo project is on oral bioavailability and biopharmaceutics, thus the key interest of the simulation exercise is the predictive ability of the in silico methods to predict release, dissolution, permeation, and intestinal first pass. Pure bottom-up prediction of p.o. study arms can be confounded by errors in prediction of disposition. Here we attempted to account for these errors by looking at relative AUC between i.v. and p.o. simulations, however this could only be performed for the subset of APIs for which i.v. data was available. Similarly, relative AUC between p.o. formulations and oral solutions attempted to untangle the prediction of permeation and first pass extraction from that of luminal release, dissolution and potential precipitation of drug product.

Predictions of relative AUC between all p.o. formulations (other than solution) and solutions $\left(\mathrm{F}_{\text {rel }}\right)$ performed very well, with $75.0 \%, 79.2 \%$ and $100 \%$ within $2-, 3-$ and 10 -fold. Similarly predictions for $\mathrm{F}_{\text {rel }}$ between IR tablet and solution achieved $75.0 \%, 87.5 \%$ and $100 \%$ within 2-, 3-, and 10-fold. A general trend of underprediction was seen for both categories of $\mathrm{F}_{\text {rel }}$, where the AFE was 0.744 and 0.708 for p.o. vs. solution and IR tablet vs. solution, equating to 1.35 and 1.41-fold underpredictions. Correlation between predicted and observed appeared to be an improvement compared to those for $\mathrm{F}_{\text {oral }}$, with $\mathrm{R}$ of 0.443 and 0.601 and $\mathrm{CCC}$ of 0.389 and 0.504 for $\mathrm{F}_{\text {rel }}$ of p.o. and IR tablet, respectively, vs. solution (Figure 6G-I).

The general trend of underprediction for relative AUC between p.o. and solutions points to an underestimation of the extent of dissolution and/or release. However, this was a very slight negative bias on average, and the correlations between predicted and observed $\mathrm{F}_{\text {rel }}$ were in general very good, especially compared to that for $\mathrm{F}_{\text {oral }}$. This suggests the models for dissolution and/or release perform well and consistently across different extents of dissolution. 
There was a debate prior to the start of the simulation exercise as to whether the clinical i.v. study arms should be unblinded. This could have allowed for the use of observed elimination and distribution to inform disposition characteristics, shifting the focus of the performance of predictions to the behaviour of oral formulations along the intestine (i.e. release, dissolution, and permeation). However, there was also an interest in evaluating the performance of completely prospective predictions as one might do in practice, particularly in FIM study designs, necessitating the i.v. profiles remain blinded throughout the simulation exercise. Alternatively, a stepwise approach could have been adopted whereby all i.v. predictions were performed in one step, followed by an unblinding of the i.v. data with p.o. predictions following. However, given that there was a time constraint due to the urgency in opening up the database for use with other tasks within the OrBiTo, this was not undertaken. 

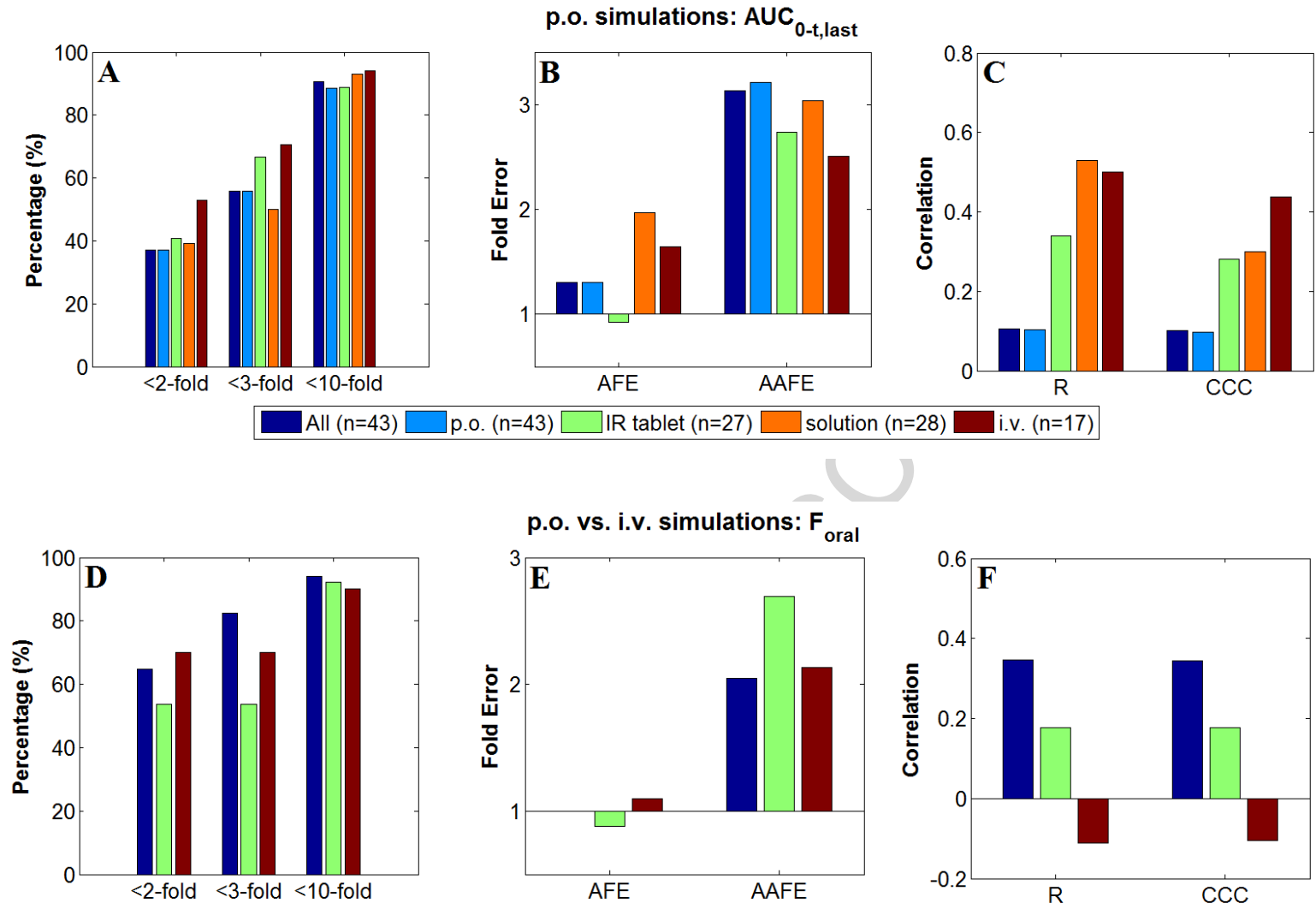

p.o. $(n=17) \square$ IR tablet $(n=13) \square$ solution $(n=10)$

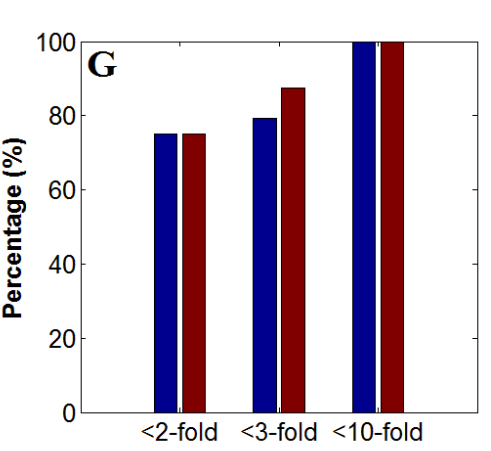

p.o. vs. solution simulations: $F_{\text {rel }}$
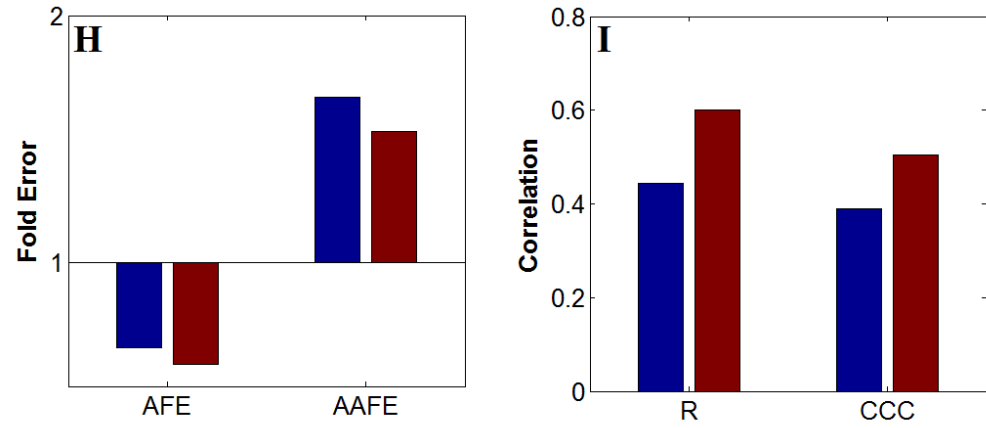

p.o. vs. solution $(n=24) \quad$ IR tablet vs. solution $(n=16)$

Figure 6. Prediction metrics for $\mathrm{AUC}_{0-\mathrm{t}, \text { last }}(\mathrm{A}-\mathrm{C}), \mathrm{F}_{\text {oral }}$ between p.o. and i.v. simulations (D-F) and $F_{\text {rel }}$ between p.o. and solution simulations $(\mathrm{G}-\mathrm{I}) ;<\mathrm{n}$-fold $=\%$ APIs within $\mathrm{n}$-fold;

\subsection{Comparison to literature exercises}

The overall performance of the OrBiTo simulation exercise was comparable to previous large-scale PBPK model evaluations (Tannergren et al., 2004; Jones et al., 2011; Poulin et al., 
2011b). However, i.v. predictions tended to perform slightly worse and oral predictions slightly better than those in the literature (Figure 7A,B), with both i.v. and p.o. overpredicting $\mathrm{AUC}_{0-\mathrm{t}, \text { last. }}$ This overprediction in exposure can be attributed to general underpredictions in i.v. clearance (Figure 7C,D), as the overall bias in predictions of i.v. Vss and oral Vd/F were comparable to, if not better than, the other exercises (Figure 7E,F). As additional evidence, $F_{\text {oral }}$ was generally well predicted (Figure 6D-F) compared to the trend of overpredictions for absolute $\mathrm{AUC}_{0-\mathrm{t} \text {,last }}$ (Figure $6 \mathrm{~A}-\mathrm{C}$ ), pointing again to underpredictions of $\mathrm{CL}$ or $\mathrm{V}_{\mathrm{ss}}$ as a potential source for the overprediction of drug exposure. An underprediction of CL may also contribute to an overprediction of $\mathrm{F}_{\text {oral }}$, through an underprediction of hepatic and intestinal first pass metabolism. However, it was difficult to assess this due to general lack of information regarding extent of intestinal metabolism with only 2/43 APIs reporting information on individual CYPs contributing to the overall clearance based on recombinant CYP in vitro data.

On average i.v. $\mathrm{AUC}_{0-\mathrm{t}, \text { last }}$ was slightly overpredicted with an $\mathrm{AFE}$ of 1.64, vs. AFE of 0.72 and 0.92 for Poulin 2011 ( $\mathrm{V}_{\mathrm{ss}}$ : JA, CL: FCIM) and ( $\mathrm{V}_{\mathrm{ss}}: \mathrm{TCK}_{\mathrm{pu}}, \mathrm{CL}$ : IVIVE), respectively (Figure 7; Table A1). The percentage of predictions falling within two-fold of observed data was slightly lower as compared to Poulin 2011, with 53\% for OrBiTo vs. $67 \%$ and $71 \%$ for Poulin ( $\mathrm{V}_{\mathrm{ss}}$ : JA, CL: FCIM) and ( $\mathrm{V}_{\mathrm{ss}}$ : $\mathrm{TCK}_{\mathrm{pu}}, \mathrm{CL}$ : IVIVE) (Poulin et al., 2011b). Oral AUC $\mathrm{A}_{0-}$ t,last was slightly overpredicted on average with AFE 1.30, however this outperformed most comparative PBPK M\&S studies, where Poulin 2011: AFE ranging from 0.14 to 0.41 for different absorption and solubility estimates and De Buck 2007: method 1 AFE 5.09 (in silico volume of distribution and traditional IVIVE of metabolic clearance). The OrBiTo simulations underperformed compared to De Buck 2007 method 2 which displayed AFE of 
1.06 (Rat $\mathrm{K}_{\mathrm{p}}$ 's scaled to human, and metabolic clearance using IVIVE while ignoring effects of $\mathrm{fu}_{\mathrm{p}} / \mathrm{BP}$ and $\left.\mathrm{fu}_{\mathrm{inc}}\right)$ (Figure 7A,B; Table A1).

Intravenous CL was in general underpredicted for OrBiTo simulations (AFE 0.48, or a 2.08 fold underprediction), with only De Buck Method 1 underperforming compared to OrBiTo (AFE of 0.415, or 2.41-fold underprediction). Further, CL predictions for OrBiTo displayed a high degree of bias between predicted and observed data (AAFE of 2.97), comparable to that of De Buck Method 1 (AAFE 2.60), but higher than most other comparable exercises which displayed AAFE of 1.5 to 1.9 (Figure 7C,D; Table A2). It has been documented that in vitro systems tend to underpredict in vivo CL (Takeuchi et al., 1998). This is in agreement with the noticeable underpredictions of the IVIVE methods of Poulin et al. (2011) and De Buck et al. (2007) Method 1, and the underpredictions of CL in the current exercise, as the majority were informed by in vitro CL measurements.

Predictions of $\mathrm{V}_{\mathrm{ss}}$ for OrBiTo simulations showed a slight overprediction with an AFE of 1.28 (n APIs=17), performing better compared to most other studies (AFE 2 to 2.1), except for De Buck $V_{d}$ Method 2 (based on preclinical tissue:plasma partition coefficients) which performed better with a reported AFE of 1.14. Predictions of oral $V_{d} / F$ also showed a slight overprediction on average, with AFE of 1.3, however performed better than De Buck Methods 1 and 2, with reported AFE of 1.38 and 0.0758 (1.32-fold underprediction), respectively. Despite the overall average trend performing relatively well compared with other literature exercises, the predictions of intravenous $V_{s s}$ and oral $V_{d} / F$ showed high variability for OrBiTo simulations (AAFE of 2.66 and 2.9), with only De Buck $V_{d}$ method 1 showing higher variability (AAFE 3.50 and 4.79, for $\mathrm{V}_{\mathrm{ss}}$ and $\mathrm{V}_{\mathrm{d}} / \mathrm{F}$; Figure 7E,F; Table A3). 



B

C

Fold error $\mathrm{CL}$

D

${ }^{\mathrm{a}}(\mathrm{Vd} 1, \mathrm{CL} 1)$,
${ }^{\mathrm{b}}(\mathrm{Vd} 2, \mathrm{CL} 2)$
${ }^{\mathrm{c}} \mathrm{CLR}$,
${ }^{d}$ PBPK (Gastroplus)
e 1 comp model
fPBPK (Vss, JA; CL, FCIM),
gPBPK (Vss, TCKpu; CL, IVIVE),
h(ka, Fabs1),
i (ka, Fabs2),
(est Solfassif),
k(meas Solfassif),

Figure 7. Prediction metrics for i.v. and p.o. AUC0-t,last (A, B), i.v. CL (C,D) and i.v. Vss or p.o. Vd/F (E,F), compared with other physiologically-based pharmacokinetic (PBPK)

simulation studies in the literature (Tannergren et al., 2004; Jones et al., 2011; Poulin et al., 2011b). ${ }^{a}\left(V_{d} 1, C L 1\right)=$ Prediction of $V_{s s}$ using Poulin and Theil method, prediction of hepatic CL

using IVIVE from human liver microsomes or hepatocytes alternatively using glomerular filtration rate ratio to predict renal $\mathrm{CL} ;{ }^{\mathrm{b}}\left(\mathrm{V}_{\mathrm{d}} 2, \mathrm{CL} 2\right)=$ Predicting $\mathrm{V}_{\mathrm{ss}}$ from rat tissue:plasma partition coefficients obtained experimentally or if not available calculated via tissue composition-based Rodgers and Rowland method, predicting CL using in vitro-in vivo extrapolation (IVIVE) not considering binding; ${ }^{\mathrm{c}} \mathrm{CL}_{\mathrm{R}}=$ renal clearance; ${ }^{\mathrm{d}} \mathrm{PBPK}$ (GastroPlus) $=$ using GastroPlus ACAT model coupled with full PBPK distribution model; ${ }^{\mathrm{e}} 1$ comp model = using one-compartment approach; ${ }^{\mathrm{f}} \mathrm{PBPK}\left(\mathrm{V}_{\mathrm{ss}}, \mathrm{JA} ; \mathrm{CL}, \mathrm{FCIM}\right)=$ Prediction of tissue:plasma partition coefficients $\left(\mathrm{K}_{\mathrm{p}}\right.$ 's) from rat volume of distribution at steady state following i.v. infusion $\left(\mathrm{V}_{\mathrm{ss}}\right)$ and lipophilicity (JA), scaling of 
clearance $(\mathrm{CL})$ using fraction unbound $\left(\mathrm{f}_{\mathrm{u}}\right)$ correlated intercept method (FCIM) allometry; ${ }^{\mathrm{g}} \mathrm{PBPK}\left(\mathrm{V}_{\mathrm{ss}}\right.$, $\mathrm{TCK}_{\mathrm{pu}}$; CL, IVIVE) $=$ Predicting $\mathrm{V}_{\mathrm{ss}}$ using Rodgers and Rowland model, in vitro-in vivo extrapolation of $\mathrm{CL} ;{ }^{\mathrm{h}}\left(\mathrm{k}_{\mathrm{a}}, \mathrm{F}_{\mathrm{abs}}\right)=\mathrm{k}_{\mathrm{a}}$ and $\mathrm{f}_{\mathrm{a}}$ from average observed in vivo preclinical $\mathrm{k}_{\mathrm{a}}$ and $\mathrm{f}_{\mathrm{a}}$ estimated from $\mathrm{F}_{\text {oral }}$ and $\mathrm{CL} ;{ }^{\mathrm{i}}\left(\mathrm{k}_{\mathrm{a}}, \mathrm{F}_{\mathrm{abs} 2}\right)=\mathrm{k}_{\mathrm{a}}$ from average observed in vivo preclinical $\mathrm{k}_{\mathrm{a}}$ and $\mathrm{f}_{\mathrm{a}}$ from average in vivo preclinical $\mathrm{F}_{\text {oral }}$ and $\mathrm{CL} ;{ }^{\mathrm{j}}($ est Solfassif $)=$ using estimated solubility in fasted simulated small intestinal fluid $(\mathrm{FaSSIF}) ;{ }^{\mathrm{k}}$ (meas Solfassif $)=$ using measured FaSSIF .

Zhang et al. recently reviewed prospective predictions of human pharmacokinetics for 18 Novartis compounds (Chang and Leblond, 1971). Their analysis revealed that high prediction accuracy in human PK parameters can be achieved when observed in vivo preclinical i.v. data were used to predict human i.v. profiles, which were then combined with mechanism-based absorption modelling to predict human PK for orally dosed compounds. The a priori predictions were within twofold of observed for $80 \%$ (Cmax), 65\% (AUC), 65\% (CL/F), and $80 \%(\mathrm{Vss} / \mathrm{F})$ of the compounds. This implies that inclusion of animal PK data can significantly improve the prediction of human PK parameters and thus prediction of human oral drug exposure. The data available for the OrBiTo exercise was sparse in this area, with approximately $60 \%$ of the APIs having preclinical i.v. data available for allometric scaling, and approximately 50\% having data for multiple species (Margolskee et al. - Part 1 Submitted). Additionally, since one of the interests was to test modeller differences, modellers were given the option of which information to use, thus there was no guarantee that preclinical data were utilised for CL predictions if in vitro CLint information was available, or that preclinical data were used to inform distribution parameters. 


\subsection{Industry perspective}

An important consideration of this study relied on the modellers to extract what they considered relevant compound information from the database. To a degree, this was limited by the sparse details provided through the interface of the database. Consequently, the form of this simulation study is not necessarily representative of how prospective modelling is carried out in the pharmaceutical industry, but may be considered a 'worst-case' scenario. Although communication was allowed between PBPK modellers and API owners through an online query system, the task suffered from poor, delayed, and sometimes absent responses. In addition, modellers carried out the task separately with limited communication with other modellers and a general absence of cross-checking, contrary to common industry practice. The overall lack of responses or data update prior to the simulation exercise did not prevent the analysis but restricted the breadth of the selected compounds. The effort needed to upload datasets in the OrBiTo database precluded EFPIA partners to generate new data in time for the simulation exercise. From the analysis of missing information, there is room for improvement and the EFPIA partners were asked to complete their datasets with missing information to inform and evaluate model improvements.

Pharmaceutical industry generally employs a learn-and-confirm approach for PBPK model development in drug discovery. In short, this entails an initial modelling phase followed by validation and if unacceptable performance is observed, further parameter data can be experimentally generated in order to improve the model. At this stage pre-clinical data can serve as an initial validation set prior to supplementing with additional information to predict human exposure. This approach has been shown to display better accuracy than simple allometric scaling. Further, the pharmaceutical industry has the advantage of the ability to 
utilise information from compounds of the same drug class or chemical structural analogues (Jones et al., 2009; Salles Junior et al., 2013; Aulinger et al., 2014). Similarly, model refinement can occur based on clinical pharmacokinetic data prior to biopharmaceutical development.

The OrBiTo simulation task did not allow for this approach due to rules setup for blinding data and general lack of supplementation of novel parameter information. Due to the blinded nature of the exercise, modellers were asked to run bottom-up anticipation of all human PK profiles with very limited time to familiarise themselves with the drug substance and drug product properties, and no time to discuss the in vitro or preclinical in vivo performance with the experts. While the setup of the database enabled for anonymous contribution and maintenance of data, and a means to facilitate unbiased evaluation, it also prevented important quality control mechanisms from being implemented efficiently. Whenever a user had a doubt about the validity of a measurement, the anonymous messaging system was the only route for resolving the issue, since identifying characteristics of the APIs were intentionally blinded or systematically altered (e.g. rounding of MW to the nearest ten). The blinded nature of the database also made it impossible to use pre-existing knowledge and information of similar compounds in model building, which is often done in industry. Importantly, the modellers conducted the simulations based on "their" selection of what they considered to be appropriate data contained within the database. Any missing information was completed using in silico tools, whereas in the industry this would have led to discussion and generation of additional in vitro and in vivo preclinical data, supported by sensitivity analysis to inform which data are critical for improving model quality. The results of this exercise should therefore not be taken out of context, i.e. be seen as an evaluation of the PBPK approach in drug discovery or biopharmaceutical development, but rather as an 
evaluation of the software prediction performance with respect to input parameters. In our companion paper we discuss the influence of compound specific properties and the identification of areas of improvement in the models and inputs (Darwich et al. - Part 3 Submitted).

Also depending on the timing of the exercise, the aim of PBPK modelling may vary in the industry and could allow for the use of more or less precise models. For example, prior to FIM testing, the pharmaceutical industry is concerned with predicting oral performance and dose-response characteristics of the clinical intended formulations to aid in the choice of that formulation. The usual target formulation for FIM is sought to achieve linear dose response up to roughly twice the predicted human pharmacological exposure in order to demonstrate human drug safety using a given formulation prior to larger scale human studies and, ideally, to demonstrate that the therapeutic dose is lower than the maximum tolerated dose (MTD) (Figure 8). In this respect, rather than the absolute pharmacokinetic profiles, the prediction of the relative performance of standard vs enhanced formulations is explored. Typically the bottom-up exercises performed at this stage are to evaluate dose linearity and relative exposure between different types of formulations so as to guide the choice of FIM formulation development. The FDA recommended method for choosing the maximum recommended starting human dose is primarily based on preclinical safety, scaling factors and application of safety margins (Karam et al., 2003), though some companies use PBPK modelling in combination with target potency and animal pharmacology to select this subefficacious starting dose. The lower dose of the FDA or the mechanistic approaches is then selected for optimal safety. 


\section{Form. 3}

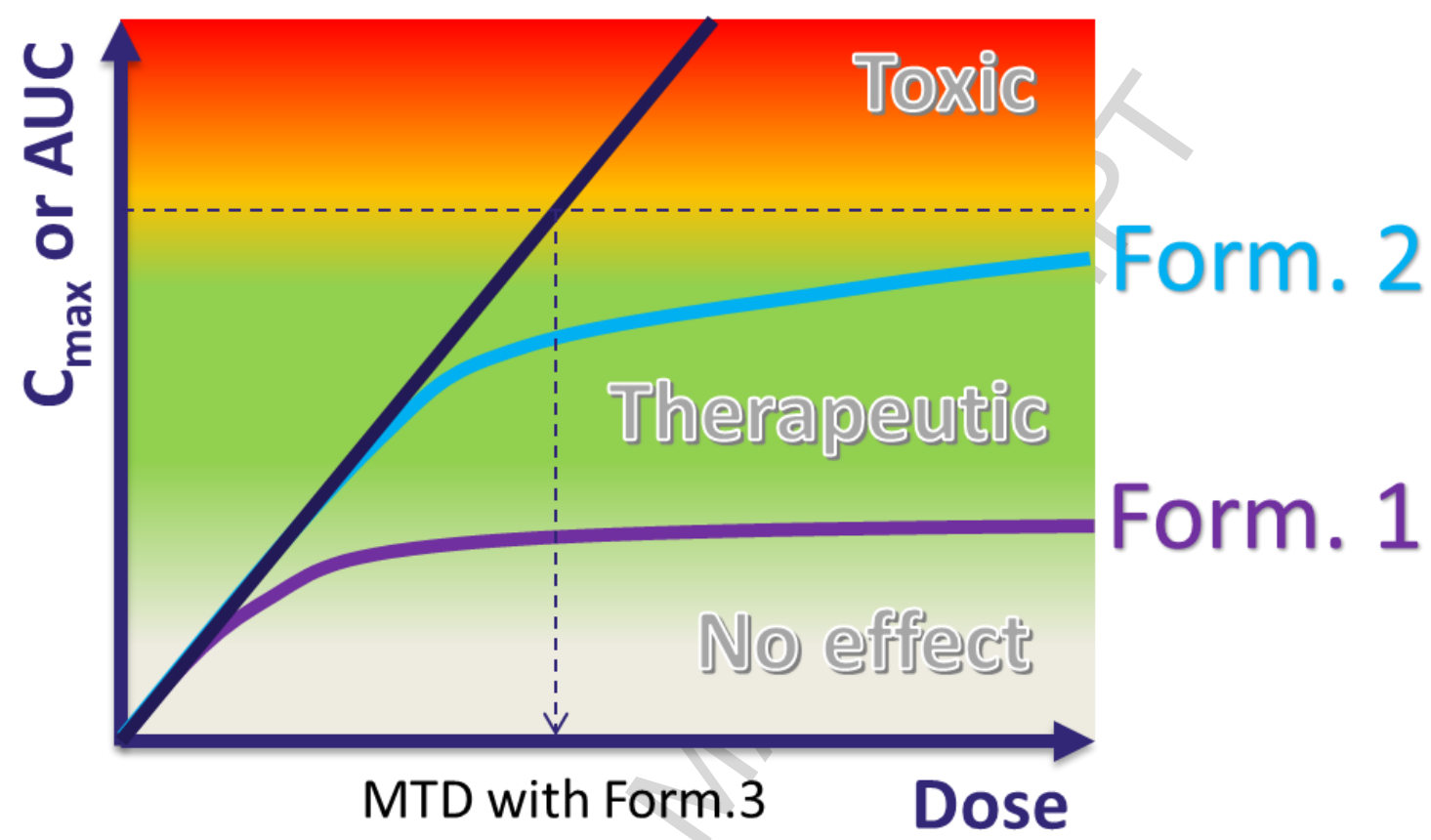

Figure 8: Evaluating relative exposure between different types of formulations can help guide choice of first time in man (FIM) formulation development. In order to explore the threshold for human safety, the target formulation for FIM is sought to achieve linear dose-response up to roughly twice the anticipated level of therapeutic response, ideally to be able to demonstrate that the therapeutic dose is lower than the maximal tolerated dose (MTD).

Due to errors in predicting an accurate $\mathrm{V}_{\mathrm{d}}$ or $\mathrm{CL}$ in man (as was highlighted in this exercise) FIM data are generally utilised to inform the PBPK models and make adjustments to the clearance and distribution parameters used as inputs into the models. In parallel approaches, human i.v. PK profile measurements using microdosing, though uncommon, are also employed during phase I with oral co-administration or prior to phase I to avoid the pitfalls of predicting human clearance and distribution volumes using a full PBPK approach. In conclusion, pure bottom-up anticipation in the industry is used prior to human testing to 
enable phase I clinical formulation choice where relative changes or linearity in dose exposure is determined. Once human data are obtained a mixed approach is employed where human data at one dose are used to predict the exposure at the next dose level or where fasted state data are used to predict fed state exposures.

\section{Conclusion}

In this study we present the largest effort to date in evaluating physiologically-based pharmacokinetic absorption models in a biopharmaceutics context. The work carried out in setting up the database, populating API files and modelling and simulation of compounds was a joint effort between European pharmaceutical industry, commercial enterprises and involved academic institutions. A modelling exercise that tests the differences in user and software selections based on the same available information has not been attempted previously. While the average predictive performance did not seem related to institution type, level of experience, or software package, there was a high level of variability in predictions for some individual APIs. The greatest variability in average prediction performance was observed across different APIs. The reasons for these API-specific differences could be related to compound specific properties, which will be explored in the companion paper (Darwich et al. - Part 3 - Submitted), the quality and availability of information for building each model, or errors in scaling from in vitro and preclinical in vivo data to human in vivo behaviour.

The overall predictive performance of the simulations indicated a slight overprediction of exposure on average, with 25 of the 43 simulated APIs producing overpredictions on average. Predictive performance declined progressing from i.v. to solution to p.o. formulations, indicating the compounding error with increased model complexity. However, predictive 
performance of $F_{\text {oral }}$ was relatively consistent, thus better predictions of CL and $V_{d}$ and/or availability of i.v. data are important for the ability to model oral formulations effectively.

The overall success of predicting i.v. and p.o. data is also highly dependent upon the data used for simulations. The limitations of data availability and individual approaches to modelling may have contributed to decreased prediction performance as compared to the process in industry which generally involves open discussion, a learn and confirm approach to model building, and additional data collection for model improvement and validation.

\section{Acknowledgements}

This work was performed under the OrBiTo Project, which has received support from the Innovative Medicines Joint Undertaking (http://www.imi.europa.eu) under Grant Agreement No. 115369. The authors would also like to acknowledge the contributions of all participants in the OrBiTo simulation exercise, especially those who could not be named in the author list. The extensive list of participants and their affiliations follows below, organised in decreasing order of workload by institution, and then alphabetical order by last name:

\begin{tabular}{|l|l|l|}
\hline Name & Affiliation(s) & Contributions(s) \\
\hline Leon Aarons & University of Manchester & PI for University of Manchester \\
\hline Adam S. Darwich & University of Manchester & $\begin{array}{l}\text { Performed gap analysis on database, } \\
\text { performed simulations, analysed results }\end{array}$ \\
\hline Aleksandra Galetin & University of Manchester & PI for University of Manchester \\
\hline Alison Margolskee & University of Manchester & $\begin{array}{l}\text { Performed gap analysis on database, } \\
\text { performed simulations, analysed results }\end{array}$ \\
\hline Amin Rostami-Hodjegan & $\begin{array}{l}\text { University of } \\
\text { Manchester/SimCYP }\end{array}$ & $\begin{array}{l}\text { Work package co-leader, PI for University } \\
\text { of Manchester, PI for SimCYP }\end{array}$ \\
\hline Sara Carlert & AstraZeneca & Performed simulations, analysed results \\
\hline Maria Hammarberg & AstraZeneca & Performed simulations \\
\hline Constanze Hilgendorf & AstraZeneca & Performed simulations \\
\hline Pernilla Johansson & AstraZeneca & Performed simulations \\
\hline Eva Karlsson & AstraZeneca & Performed simulations \\
\hline Donal Murphy & AstraZeneca & Performed simulations \\
\hline
\end{tabular}




\begin{tabular}{|c|c|c|}
\hline Christer Tannergren & AstraZeneca & Performed simulations, PI for AstraZeneca \\
\hline Helena Thörn & AstraZeneca & Performed simulations \\
\hline Mohammed Yasin & AstraZeneca & Performed simulations \\
\hline Florent Mazuir & Sanofi & Performed simulations \\
\hline Olivier Nicolas & Sanofi & Performed simulations, analysed results \\
\hline Xavier Pepin & Sanofi/AstraZeneca & $\begin{array}{l}\text { Work package co-leader, PI for Sanofi until } \\
\text { March } 2015 \text {, performed gap analysis on } \\
\text { database, performed simulations, analysed } \\
\text { results }\end{array}$ \\
\hline Sergej Ramusovic & Sanofi & Performed simulations \\
\hline Christine Xu & Sanofi & Performed simulations \\
\hline Shriram Pathak & SimCYP & $\begin{array}{l}\text { Performed gap analysis on database, } \\
\text { performed simulations, analysed results }\end{array}$ \\
\hline Timo Korjamo & Orion Pharma & Performed simulations, analysed results \\
\hline Johanna Laru & Orion Pharma & Performed simulations \\
\hline Jussi Malkki & Orion Pharma & Performed simulations, analysed results \\
\hline Sari Pappinen & Orion Pharma & Analysed results \\
\hline Johanna Tuunainen & Orion Pharma & Analysed results \\
\hline Jennifer Dressman & Goethe University & PI for Goethe University \\
\hline Carmen Gött & Goethe University & Analysed results \\
\hline Simone Hansmann & Goethe University & Performed simulations, analysed results \\
\hline Edmund Kostewicz & Goethe University & PI for Goethe University \\
\hline Handan He & Novartis & Performed simulations, analysed results \\
\hline Tycho Heimbach & Novartis & Performed simulations, analysed results \\
\hline Fan Wu & Novartis & Performed simulations, analysed results \\
\hline Carolin Hoft & AbbVie & Performed simulations \\
\hline Loic Laplanche & AbbVie & PI for Abbvie, analysed results \\
\hline Yan Pang & AbbVie & Performed simulations \\
\hline Michael B. Bolger & Simulations Plus & $\begin{array}{l}\text { PI for Simulations Plus, lead for analysis of } \\
\text { impact of solubility and dissolution }\end{array}$ \\
\hline John DiBella & Simulations Plus & $\begin{array}{l}\text { Financial and time accounting for } \\
\text { Simulations Plus }\end{array}$ \\
\hline Eva Huehn & Simulations Plus & $\begin{array}{l}\text { Performed gap analysis on database, } \\
\text { performed simulations }\end{array}$ \\
\hline Viera Lukacova & Simulations Plus & Co-PI for Simulations Plus \\
\hline James M. Mullin & Simulations Plus & $\begin{array}{l}\text { Performed gap analysis on database, } \\
\text { performed simulations }\end{array}$ \\
\hline Ke X. Szeto & Simulations Plus & $\begin{array}{l}\text { Performed gap analysis on database, } \\
\text { performed simulations }\end{array}$ \\
\hline Chester Costales & Pfizer & Performed simulations \\
\hline Jian Lin & Pfizer & Performed simulations \\
\hline Mark McAllister & Pfizer & Performed simulations \\
\hline Sweta Modi & Pfizer & Performed simulations \\
\hline Charles Rotter & Pfizer & Performed simulations \\
\hline Manthena Varma & Pfizer & Performed simulations \\
\hline Mei Wong & Pfizer & Performed simulations \\
\hline Amitava Mitra & $\begin{array}{l}\text { Merck Sharp \& Dohme } \\
\text { (MSD) }\end{array}$ & Performed simulations, analysed results \\
\hline Jan Bevernage & Janssen & Performed simulations \\
\hline
\end{tabular}




\begin{tabular}{|l|l|l|}
\hline Jeike Biewenga & Janssen & Performed simulations \\
\hline Achiel Van Peer & Janssen & Performed simulations \\
\hline Richard Lloyd & GlaxoSmithKline & Performed simulations, analysed results \\
\hline Carole Shardlow & GlaxoSmithKline & Performed simulations, analysed results \\
\hline Peter Langguth & University of Mainz & PI for University of Mainz \\
\hline Irina Mishenzon & University of Mainz & Performed simulations \\
\hline Mai Anh Nguyen & University of Mainz & Performed simulations \\
\hline Jonathan Brown & Bristol-Myers Squibb & Performed simulations \\
\hline
\end{tabular}

\section{References}

Darwich AS, Margolskee A, Pepin X, Aarons L, Galetin A, Rostami-Hodjegan A, Carlert S, Hammarberg M, Hilgendorf C, Johansson P, Karlsson E, Murphy D, Tannergren C, Thörn H, Yasin M, Mazuir F, Nicolas O, Ramusovic S, Xu C, Pathak SM, Korjamo T, Laru J, Malkki J, Pappinen S, Tuunainen J, Dressman J, Hansmann S, Kostewicz E, He H, Heimbach T, Wu F, Hoft C, Pang Y, Bolger MB, Huehn E, Lukacova V, Mullin JM, Szeto KX, Costales C, Lin J, McAllister M, Modi S, Rotter C, Varma M, Wong M, Mitra A, Bevernage J, Biewenga J, Van Peer A, Lloyd R, Shardlow C, Langguth P, Mishenzon I, Nguyen MA, Brown J, Lennernäs H, and Abrahamsson B (Submitted) IMI - Oral Biopharmaceutics Tools project - Evaluation of Bottom-up PBPK Prediction Success Part 3: Influence of Compound Specific Properties. Eur J Pharm Sci.

Aulinger BA, Bedorf A, Kutscherauer G, de Heer J, Holst JJ, Goke B, and Schirra J (2014) Defining the role of GLP-1 in the enteroinsulinar axis in type 2 diabetes using DPP-4 inhibition and GLP-1 receptor blockade. Diabetes 63:1079-1092.

Bredael GM, Bowers N, Boulineau F, and Hahn D (2014) In vitro-in vivo correlation strategy applied to an immediate-release solid oral dosage form with a biopharmaceutical classification system IV compound case study. J Pharm Sci 103:2125-2130.

Bueters T, Ploeger BA, and Visser SA (2013) The virtue of translational PKPD modeling in drug discovery: selecting the right clinical candidate while sparing animal lives. Drug discovery today 18:853-862.

Chang WW and Leblond CP (1971) Renewal of the epithelium in the descending colon of the mouse. I. Presence of three cell populations: vacuolated-columnar, mucous and argentaffin. Am J Anat 131:73-99.

Chen Y, Jin JY, Mukadam S, Malhi V, and Kenny JR (2012) Application of IVIVE and PBPK modeling in prospective prediction of clinical pharmacokinetics: strategy and approach during the drug discovery phase with four case studies. Biopharm Drug Dispos 33:85-98.

Huang SM, Abernethy DR, Wang Y, Zhao P, and Zineh I (2013) The utility of modeling and simulation in drug development and regulatory review. J Pharm Sci 102:2912-2923.

Johnson TN, Zhou D, and Bui KH (2014) Development of physiologically based pharmacokinetic model to evaluate the relative systemic exposure to quetiapine after administration of IR and XR formulations to adults, children and adolescents. Biopharm Drug Dispos 35:341-352. 
Jones HM, Gardner IB, Collard WT, Stanley PJ, Oxley P, Hosea NA, Plowchalk D, Gernhardt S, Lin J, Dickins M, Rahavendran SR, Jones BC, Watson KJ, Pertinez H, Kumar V, and Cole S (2011) Simulation of human intravenous and oral pharmacokinetics of 21 diverse compounds using physiologically based pharmacokinetic modelling. Clin Pharmacokinet 50:331-347.

Jones HM, Gardner IB, and Watson KJ (2009) Modelling and PBPK simulation in drug discovery. AAPS J 11:155-166.

Karam SM, Straiton T, Hassan WM, and Leblond CP (2003) Defining epithelial cell progenitors in the human oxyntic mucosa. Stem cells 21:322-336.

Kesisoglou F, Xia B, and Agrawal NG (2015) Comparison of Deconvolution-Based and Absorption Modeling IVIVC for Extended Release Formulations of a BCS III Drug Development Candidate. AAPS J 17:1492-1500.

Kostewicz ES, Aarons L, Bergstrand M, Bolger MB, Galetin A, Hatley O, Jamei M, Lloyd R, Pepin X, Rostami-Hodjegan A, Sjogren E, Tannergren C, Turner DB, Wagner C, Weitschies W, and Dressman J (2013) PBPK models for the prediction of in vivo performance of oral dosage forms. Eur J Pharm Sci.

Lennernas H, Aarons L, Augustijns P, Beato S, Bolger M, Box K, Brewster M, Butler J, Dressman J, Holm R, Julia Frank K, Kendall R, Langguth P, Sydor J, Lindahl A, McAllister M, Muenster U, Mullertz A, Ojala K, Pepin X, Reppas C, RostamiHodjegan A, Verwei M, Weitschies W, Wilson C, Karlsson C, and Abrahamsson B (2013) Oral biopharmaceutics tools - Time for a new initiative - An introduction to the IMI project OrBiTo. Eur J Pharm Sci.

Messier B (1960) Renewal of the colonic epithelium of the rat. Am J Dig Dis 5:833-835.

Mitra A, Kesisoglou F, Beauchamp M, Zhu W, Chiti F, and Wu Y (2011) Using absorption simulation and gastric $\mathrm{pH}$ modulated dog model for formulation development to overcome achlorhydria effect. Mol Pharm 8:2216-2223.

Pepin XJ, Flanagan TR, Holt DJ, Eidelman A, Treacy D, and Rowlings CE (2016) Justification of Drug Product Dissolution Rate and Drug Substance Particle Size Specifications Based on Absorption PBPK Modeling for Lesinurad Immediate Release Tablets. Mol Pharm.

Poulin P, Jones HM, Jones RD, Yates JW, Gibson CR, Chien JY, Ring BJ, Adkison KK, He H, Vuppugalla R, Marathe P, Fischer V, Dutta S, Sinha VK, Bjornsson T, Lave T, and $\mathrm{Ku}$ MS (2011a) PhRMA CPCDC initiative on predictive models of human pharmacokinetics, part 1: Goals, properties of the PhRMA dataset, and comparison with literature datasets. J Pharm Sci.

Poulin P, Jones RD, Jones HM, Gibson CR, Rowland M, Chien JY, Ring BJ, Adkison KK, Ku MS, He H, Vuppugalla R, Marathe P, Fischer V, Dutta S, Sinha VK, Bjornsson T, Lave T, and Yates JW (2011b) PHRMA CPCDC initiative on predictive models of human pharmacokinetics, part 5: Prediction of plasma concentration-time profiles in human by using the physiologically-based pharmacokinetic modeling approach. $J$ Pharm Sci.

Rodgers T, Leahy D, and Rowland M (2005) Physiologically based pharmacokinetic modeling 1: predicting the tissue distribution of moderate-to-strong bases. J Pharm Sci 94:1259-1276.

Salles Junior LD, Santos PR, dos Santos AA, and de Souza MH (2013) Dyspepsia and gastric emptying in end-stage renal disease patients on hemodialysis. BMC nephrology 14:275.

Sjogren E, Westergren J, Grant I, Hanisch G, Lindfors L, Lennernas H, Abrahamsson B, and Tannergren C (2013) In silico predictions of gastrointestinal drug absorption in 
pharmaceutical product development: application of the mechanistic absorption model GI-Sim. Eur J Pharm Sci 49:679-698.

Takamatsu N, Kim ON, Welage LS, Idkaidek NM, Hayashi Y, Barnett J, Yamamoto R, Lipka E, Lennernas H, Hussain A, Lesko L, and Amidon GL (2001) Human jejunal permeability of two polar drugs: cimetidine and ranitidine. Pharm Res 18:742-744.

Takeuchi T, Kitagawa H, Imagawa T, and Uehara M (1998) Proliferation and cellular kinetics of villous epithelial cells and M cells in the chicken caecum. Journal of anatomy 193 ( Pt 2):233-239.

Tannergren C, Engman H, Knutson L, Hedeland M, Bondesson U, and Lennernas H (2004) St John's wort decreases the bioavailability of R- and S-verapamil through induction of the first-pass metabolism. Clin Pharmacol Ther 75:298-309.

Thondre PS, Shafat A, and Clegg ME (2013) Molecular weight of barley beta-glucan influences energy expenditure, gastric emptying and glycaemic response in human subjects. The British journal of nutrition 110:2173-2179.

Van den Bergh A, Sinha V, Gilissen R, Straetemans R, Wuyts K, Morrison D, Bijnens L, and Mackie C (2011) Prediction of human oral plasma concentration-time profiles using preclinical data: comparative evaluation of prediction approaches in early pharmaceutical discovery. Clin Pharmacokinet 50:505-517.

Willmann S, Thelen K, Becker C, Dressman JB, and Lippert J (2010) Mechanism-based prediction of particle size-dependent dissolution and absorption: cilostazol pharmacokinetics in dogs. Eur J Pharm Biopharm 76:83-94.

Winiwarter S, Ax F, Lennernas H, Hallberg A, Pettersson C, and Karlen A (2003) Hydrogen bonding descriptors in the prediction of human in vivo intestinal permeability. Journal of molecular graphics \& modelling 21:273-287.

Yu LX, Amidon G, Khan MA, Hoag SW, Polli J, Raju GK, and Woodcock J (2014) Understanding pharmaceutical quality by design. AAPS J 16:771-783.

\section{Appendix}

\section{Comparators}

Table A1: Summary statistics for AUC i.v. and p.o. compared with other simulation exercises from the literature.

\begin{tabular}{|c|c|c|c|c|c|c|c|c|}
\hline & $\bar{n}$ & $\begin{array}{l}\% \text { within } \\
2 \text { fold }\end{array}$ & $\begin{array}{l}\text { \% within } \\
3 \text { fold }\end{array}$ & $\begin{array}{l}\% \text { within } \\
10 \text { fold }\end{array}$ & $\overline{\mathrm{AFE}}$ & $\overline{\text { AAFE }}$ & $\overline{\mathbf{R}}$ & $\begin{array}{l}\text { CCC } \\
\text { (of log } \\
\text { data) }\end{array}$ \\
\hline \multicolumn{9}{|l|}{ AUC, i.v. } \\
\hline Poulin 2011 $^{\mathrm{f}}$ & 15 & 67 & 87 & 93 & 0.72 & 1.9 & 0.99 & 0.93 \\
\hline Poulin 2011 $^{\mathrm{g}}$ & 14 & 71 & 93 & 100 & 0.92 & 1.8 & 0.52 & 0.92 \\
\hline OrBiTo & 17 & 53 & 71 & 94 & 1.64 & 2.51 & 0.500 & 0.870 \\
\hline
\end{tabular}




\begin{tabular}{|c|c|c|c|c|c|c|c|c|}
\hline AUC, p.o. & & & & & & & & \\
\hline De Buck 2007 & 23 & 34.8 & 43.5 & $69.6^{*}$ & 5.09 & $5.34 *$ & $0.984 *$ & $0.577 *$ \\
\hline De Buck 2007 & 23 & 73.9 & 87 & $100 *$ & 1.06 & $1.83^{*}$ & 0.997* & $0.910^{*}$ \\
\hline Jones 2011 $^{\mathrm{d}}$ & & 50 & 72 & & & 2.7 & & \\
\hline${\text { Jones } 2011^{\mathrm{e}}}$ & & 33 & 56 & & & 3.9 & & \\
\hline Poulin 2011, & 84 & 25 & 44 & 74 & 0.17 & 11 & 0.88 & 0.45 \\
\hline Poulin 2011 ${ }^{\text {fi }}$ & 82 & 28 & 45 & 84 & 0.41 & 4.2 & 0.87 & 0.75 \\
\hline Poulin 2011 ${ }^{\mathrm{g}, \mathrm{j}}$ & 33 & 21 & 30 & 64 & 0.37 & 7.8 & 0.47 & 0.58 \\
\hline Poulin 2011 ${ }^{\mathrm{g}, \mathrm{k}}$ & 18 & 11 & 28 & 61 & 0.14 & 11.1 & 0.96 & 0.38 \\
\hline OrBiTo & 43 & 37 & 56 & 88 & 1.30 & 3.2 & 0.103 & 0.759 \\
\hline
\end{tabular}

Table A2: Summary statistics for CL i.v. compared with other simulation exercises in the literature

\begin{tabular}{|c|c|c|c|c|c|c|c|c|}
\hline & $\mathbf{n}$ & $\begin{array}{l}\text { \% within } \\
2 \text { fold }\end{array}$ & $\begin{array}{l}\text { \% within } 3 \\
\text { fold }\end{array}$ & $\begin{array}{l}\% \text { within } \\
10 \text { fold }\end{array}$ & $\overline{\text { AFE }}$ & $\overline{\text { AAFE }}$ & $\mathbf{R}$ & $\begin{array}{l}\text { CCC } \\
\text { (of log } \\
\text { data) }\end{array}$ \\
\hline \multicolumn{9}{|l|}{ CL, i.v. } \\
\hline De Buck 2007 ${ }^{\text {a }}$ & 19 & 52.6 & 68.4 & $94.7^{*}$ & 0.415 & $2.60^{*}$ & $0.443^{*}$ & $0.607^{*}$ \\
\hline De Buck 2007 & 19 & 73.7 & 89.5 & $100^{*}$ & 1.10 & $1.61^{*}$ & $0.899^{*}$ & $0.996^{*}$ \\
\hline De Buck 2007 & 4 & 100 & 100 & 100 & 1.09 & & & \\
\hline Jones 2011 $^{\mathrm{d}}$ & & 80 & 85 & & & $\overline{1.6}$ & & \\
\hline Jones 2011 $^{\mathrm{e}}$ & & 80 & 85 & & & $\overline{1.6}$ & & \\
\hline Poulin 2011 $^{\mathrm{f}}$ & $17^{*}$ & $76^{*}$ & $88^{*}$ & $100^{*}$ & $0.753^{*}$ & $1.66^{*}$ & & \\
\hline Poulin 2011 $^{\mathrm{g}}$ & $14^{*}$ & $57^{*}$ & $64 *$ & $71^{*}$ & $0.383^{*}$ & $3.27^{*}$ & & \\
\hline OrBiTo & 17 & 35 & 59 & 94 & 0.48 & 2.97 & 0.8 & 0.441 \\
\hline
\end{tabular}

Table A3: Summary statistics for Vss i.v. and Vd/F p.o. compared with other simulation exercises from the literature

\begin{tabular}{|c|c|c|c|c|c|c|c|c|}
\hline & $\mathbf{n}$ & $\begin{array}{l}\% \text { within } \\
2 \text { fold }\end{array}$ & $\begin{array}{l}\text { \% within } 3 \\
\text { fold }\end{array}$ & $\begin{array}{l}\% \text { within } \\
10 \text { fold }\end{array}$ & $\overline{\mathrm{AFE}}$ & $\overline{\text { AAFE }}$ & $\mathbf{R}$ & $\begin{array}{l}\text { CCC } \\
\text { (of log } \\
\text { data) }\end{array}$ \\
\hline \multicolumn{9}{|l|}{ Vss, i.v. } \\
\hline De Buck 2007 & 19 & 31.6 & 52.6 & $94.7^{*}$ & 2.10 & $3.50^{*}$ & $0.0356^{*}$ & $0.272^{*}$ \\
\hline De Buck 2007 & 19 & 84.2 & 94.7 & $100 *$ & 1.14 & $1.45^{*}$ & $0.811 *$ & $0.881^{*}$ \\
\hline
\end{tabular}




\begin{tabular}{|c|c|c|c|c|c|c|c|c|}
\hline Jones 2011 $^{\mathrm{d}}$ & & 90 & 100 & 100 & & 1.4 & & \\
\hline Jones 2011 ${ }^{\mathrm{e}}$ & & 75 & 85 & & & 1.6 & & \\
\hline Poulin 2011 $^{\mathrm{f}}$ & $15^{*}$ & $53^{*}$ & $73^{*}$ & $100^{*}$ & $2.09^{*}$ & $2.24 *$ & & \\
\hline Poulin 2011 $^{\mathrm{g}}$ & $17^{*}$ & $47^{*}$ & $76^{*}$ & $82^{*}$ & $1.81^{*}$ & $3.07 *$ & & \\
\hline OrBiTo & 17 & 35 & 65 & 94 & 1.28 & 2.66 & 0.49 & 0.636 \\
\hline \multicolumn{9}{|l|}{ Vd/F, p.o. } \\
\hline De Buck 2007 & 23 & 21.7 & 39.1 & $82.6^{*}$ & 1.38 & $4.79^{*}$ & $-0.103^{*}$ & $0.203^{*}$ \\
\hline De Buck 2007 & 23 & 69.6 & 82.6 & $100^{*}$ & 0.758 & $1.73^{*}$ & $0.791^{*}$ & $0.863^{*}$ \\
\hline OrBiTo & 43 & 37 & 63 & 93 & 1.3 & 2.9 & 0.598 & 0.648 \\
\hline
\end{tabular}

\section{Formulations}

Table A4: Summary statistics for PK Parameter, Foral, and Frel predictions grouped by

Formulations

\begin{tabular}{|c|c|c|c|c|c|c|c|c|c|c|}
\hline & $\begin{array}{l}\text { No. } \\
\text { APIs }\end{array}$ & $\begin{array}{l}\% \\
\text { within } \\
2 \text { fold }\end{array}$ & $\begin{array}{l}\text { \% } \\
\text { within } \\
3 \text { fold } \\
\end{array}$ & $\begin{array}{l}\% \\
\text { within } \\
10 \text { fold }\end{array}$ & $\overline{\mathrm{AFE}}$ & AAFE & $\mathbf{R}$ & $\mathrm{CCC}$ & $\begin{array}{l}R \\
\text { (of log } \\
\text { data) }\end{array}$ & $\begin{array}{l}\text { CCC } \\
\text { (of log } \\
\text { data) }\end{array}$ \\
\hline \multicolumn{11}{|l|}{ AUClast } \\
\hline All & 43 & 37.2 & 55.8 & 90.7 & 1.30 & 3.13 & 0.106 & 0.102 & 0.762 & 0.756 \\
\hline p.o. & 43 & 37.2 & 55.8 & 88.4 & 1.30 & 3.21 & 0.103 & 0.0969 & 0.766 & 0.759 \\
\hline IR tablet & 27 & 40.7 & 66.7 & 88.9 & 0.93 & 2.74 & 0.339 & 0.280 & 0.793 & 0.783 \\
\hline solution & 28 & 39.3 & 50.0 & 92.9 & 1.97 & 3.04 & 0.530 & 0.299 & 0.867 & 0.836 \\
\hline i.v. & 17 & 52.9 & 70.6 & 94.1 & 1.64 & 2.51 & 0.500 & 0.438 & 0.908 & 0.870 \\
\hline AUCinf & 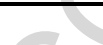 & 7 & & & & & & & & \\
\hline All & 43 & 32.6 & 44.2 & 86.0 & 1.43 & 3.65 & 0.116 & 0.0893 & 0.726 & 0.712 \\
\hline p.o. & 43 & 34.9 & 46.5 & 83.7 & 1.40 & 3.65 & 0.119 & 0.0859 & 0.739 & 0.726 \\
\hline IR tablet & 27 & 37.0 & 59.3 & 81.5 & 1.10 & 3.21 & 0.200 & 0.177 & 0.744 & 0.743 \\
\hline solution & 28 & 28.6 & 42.9 & 85.7 & 2.20 & 3.65 & 0.431 & 0.147 & 0.831 & 0.789 \\
\hline i.v. & 17 & 35.3 & 58.8 & 94.1 & 2.07 & 2.97 & 0.472 & 0.388 & 0.886 & 0.836 \\
\hline \multicolumn{11}{|l|}{ Cmax } \\
\hline p.o. & 43 & 39.5 & 62.8 & 86.0 & 0.616 & 3.19 & 0.453 & 0.452 & 0.787 & 0.756 \\
\hline IR tablet & 27 & 48.1 & 74.1 & 88.9 & 0.569 & 2.63 & 0.426 & 0.383 & 0.812 & 0.780 \\
\hline solution & 28 & 42.9 & 67.9 & 89.3 & 0.745 & 2.9 & 0.451 & 0.375 & 0.855 & 0.845 \\
\hline \multicolumn{11}{|l|}{ Tmax } \\
\hline p.o. & 43 & 53.5 & 76.7 & 95.3 & 1.30 & 2.24 & -0.0511 & -0.0462 & -0.071 & -0.0663 \\
\hline IR tablet & 27 & 59.3 & 70.4 & 96.3 & 1.10 & 2.17 & 0.0432 & 0.0393 & 0.0483 & 0.0475 \\
\hline solution & 28 & 39.3 & 67.9 & 96.4 & 1.60 & 2.63 & $\begin{array}{c}-0.108 \\
\end{array}$ & $\begin{array}{l}-0.0954 \\
\end{array}$ & $\begin{array}{l}-0.0823 \\
\end{array}$ & -0.0704 \\
\hline \multicolumn{11}{|l|}{ CL or CL/F } \\
\hline All & 43 & 32.6 & 44.2 & 88.4 & 0.675 & 3.67 & 0.265 & 0.0858 & 0.523 & 0.497 \\
\hline p.o. & 43 & 34.9 & 46.5 & 83.7 & 0.694 & 3.63 & 0.404 & 0.235 & 0.580 & 0.556 \\
\hline IR tablet & 27 & 37.0 & 59.3 & 81.5 & 0.914 & 3.19 & 0.918 & 0.910 & 0.573 & 0.564 \\
\hline solution & 28 & 28.6 & 42.9 & 85.7 & 0.441 & 3.68 & 0.656 & 0.089 & 0.617 & 0.547 \\
\hline i.v. & 17 & 35.3 & $\begin{array}{l}58.8 \\
\end{array}$ & 94.1 & 0.483 & 2.97 & 0.796 & 0.751 & 0.576 & 0.441 \\
\hline \multicolumn{11}{|l|}{ T1/2 } \\
\hline All & 43 & 53.5 & 60.5 & 93.0 & 1.91 & 2.67 & 0.680 & 0.318 & 0.525 & 0.438 \\
\hline
\end{tabular}




\begin{tabular}{|c|c|c|c|c|c|c|c|c|c|c|}
\hline p.o. & 43 & 53.5 & 60.5 & 95.3 & 1.87 & 2.61 & 0.702 & 0.284 & 0.550 & 0.459 \\
\hline IR tablet & 27 & 59.3 & 66.7 & 100 & 1.62 & 2.51 & 0.635 & 0.170 & 0.413 & 0.355 \\
\hline solution & 28 & 32.1 & 46.4 & 89.3 & 2.66 & 3.60 & 0.544 & 0.308 & 0.329 & 0.232 \\
\hline i.v. & 17 & 35.3 & 64.7 & 94.1 & 1.88 & 2.89 & 0.963 & 0.901 & 0.543 & 0.484 \\
\hline \multicolumn{11}{|l|}{ Vd or $V d / F$} \\
\hline All & 43 & 34.9 & 62.8 & 93.0 & 1.29 & 2.86 & 0.173 & 0.163 & 0.631 & 0.617 \\
\hline p.o. & 43 & 37.2 & 62.8 & 93.0 & 1.30 & 2.90 & 0.598 & 0.592 & 0.661 & 0.648 \\
\hline IR tablet & 27 & 51.9 & 77.8 & 96.3 & 1.48 & 2.23 & 0.753 & 0.735 & 0.762 & 0.731 \\
\hline solution & 28 & 39.3 & 57.1 & 85.7 & 1.17 & 3.15 & 0.213 & 0.119 & 0.554 & 0.551 \\
\hline i.v. & 17 & 35.3 & 52.9 & 94.1 & 0.909 & 3.07 & 0.412 & 0.253 & 0.640 & 0.636 \\
\hline AUMC0-t & & & & & & $\overline{4}$ & $\bar{c}$ & & & \\
\hline All & 43 & 18.6 & 41.9 & 76.7 & 2.47 & 5.90 & -0.00234 & -0.00113 & 0.662 & 0.621 \\
\hline p.o. & 43 & 18.6 & 41.9 & 72.1 & 2.49 & 6.01 & -0.00327 & -0.00153 & 0.666 & 0.624 \\
\hline IR tablet & 27 & 25.9 & 40.7 & 77.8 & 1.35 & 4.33 & 0.245 & 0.234 & 0.698 & 0.674 \\
\hline solution & 28 & 25.0 & 46.4 & 60.7 & 5.21 & 6.70 & 0.367 & 0.0825 & 0.776 & 0.658 \\
\hline i.v. & 17 & 29.4 & 47.1 & 70.6 & 3.24 & 5.20 & -0.0006 & -0.00038 & 0.772 & 0.707 \\
\hline AUMCinf & & & & & 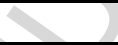 & & & & & \\
\hline All & 43 & 20.9 & 32.6 & 62.8 & 3.27 & 8.30 & 0.0308 & 0.00517 & 0.563 & 0.505 \\
\hline p.o. & 43 & 20.9 & 32.6 & 60.5 & 3.13 & 8.06 & 0.0327 & 0.00524 & 0.595 & 0.539 \\
\hline IR tablet & 27 & 25.9 & 33.3 & 66.7 & 2.05 & 6.98 & 0.0357 & 0.00657 & 0.569 & 0.546 \\
\hline solution & 28 & 17.9 & 28.6 & 57.1 & 6.95 & 10.5 & 0.0696 & 0.0134 & 0.650 & 0.518 \\
\hline i.v. & 17 & 23.5 & 35.3 & 58.8 & 5.50 & 8.39 & 0.00665 & 0.00321 & 0.692 & 0.587 \\
\hline MRT or MTT & & & & $+\infty$ & & & & & & \\
\hline All & 43 & 32.6 & 60.5 & 88.4 & 2.29 & 2.94 & 0.645 & 0.199 & 0.485 & 0.358 \\
\hline p.o. & 43 & 34.9 & 60.5 & 88.4 & 2.23 & 2.84 & 0.643 & 0.180 & 0.501 & 0.370 \\
\hline IR tablet & 27 & 40.7 & 66.7 & 100 & 1.87 & 2.5 & 0.682 & 0.182 & 0.483 & 0.384 \\
\hline solution & 28 & 14.3 & 42.9 & 85.7 & 3.16 & 4.00 & 0.537 & 0.231 & 0.351 & 0.220 \\
\hline i.v. & 17 & 23.5 & 52.9 & 82.4 & 2.65 & 3.73 & 0.968 & 0.616 & 0.524 & 0.407 \\
\hline $\begin{array}{l}\text { Foral (p.o. vs. } \\
\text { i.v.) }\end{array}$ & & & $\theta$ & & & & & & & \\
\hline p.o. & 17 & 64.7 & 82.4 & 94.1 & 1.00 & 2.05 & 0.346 & 0.345 & 0.383 & 0.380 \\
\hline IR tablet & 13 & 53.8 & 53.8 & 92.3 & 0.893 & 2.69 & 0.178 & 0.176 & 0.150 & 0.149 \\
\hline solution & 10 & 70.0 & 70.0 & 90.0 & 1.10 & 2.13 & -0.111 & -0.106 & -0.0272 & -0.0269 \\
\hline $\begin{array}{l}\text { Frel (p.o. vs. } \\
\text { solution) }\end{array}$ & - & $\overline{7}$ & & & & & & & & \\
\hline $\begin{array}{l}\text { p.o. vs. } \\
\text { solution }\end{array}$ & 24 & 75.0 & 79.2 & 100 & 0.744 & 1.67 & 0.443 & 0.389 & 0.333 & 0.269 \\
\hline $\begin{array}{l}\text { tablet vs. } \\
\text { solution }\end{array}$ & 16 & 75.0 & 87.5 & 100 & 0.708 & 1.53 & 0.601 & 0.504 & 0.472 & 0.334 \\
\hline
\end{tabular}

